\title{
MOVIMIENTO DEFENSORES DEL AGUA DE PIEDECUESTA, SANTANDER, COLOMBIA (1995-2005)
}

\author{
ARIEL EDMUNDO TARAZONA PEDRAZA²
}

Recibido el 7 de junio de 2011 y aprobado el 20 de noviembre de 2012

\section{RESUMEN}

Por medio de la Investigación Acción Participación se sistematiza la articulación de un movimiento social local que afrontó luchas globales en contra de los macroproyectos, por la usurpación del recurso agua y defensa de ecosistemas frágiles que se veían afectados por la Ampliación del Acueducto del Área Metropolitana de Bucaramanga. El movimiento se originó en la localidad de Piedecuesta (Santander, Colombia) y como una red (Cohen \& Arato, 2000; Melucci, 2002) se extendió por diferentes nodos, a los municipios de Guaca, Tona y el Área Metropolitana de Bucaramanga. Para este caso concreto del Movimiento Defensores del Agua, se aplica lo teorizado por Cohen y Arato (2000) en la reconstrucción de la sociedad civil, y es utilizar dos de los grandes paradigmas de los movimientos sociales, el de la movilización de recursos y el de los "nuevos movimientos sociales", para de esta manera hacer más comprensible los movimientos sociales contemporáneos. El marco de acción de la lucha del Movimiento Defensores del Agua se da dentro de la Constitución de 1991, donde se postula un Estado Social de Derecho inmerso en Economía de Mercado (Jiménez, 2008); de allí se desprende todo un torrente legislativo como la Ley 134 de Participación Ciudadana que reglamenta los Cabildos Abiertos, y la Ley 99 de 1993 del Medio Ambiente que en su artículo 72 alude a las Audiencias Públicas Ambientales, mecanismos estos que son utilizados por el Movimiento en cuestión como instrumento de lucha. El artículo deja entrever el papel de los profesionales en el movimiento social, el diálogo de saberes entre el saber popular y el saber científico que estructuran el movimiento, el papel de las organizaciones no gubernamentales en la lógica del Estado neoliberal (Escobar, Álvarez \& Dagnino, 2001). Se evidenciará la génesis y evolución de un movimiento social y su transformación, sus logros, tales como la solidaridad alcanzada, la cultura política generada tanto en la propia sociedad civil como del Estado. Las convocatorias a espacios simbólicos y contrapúblicos (Escobar, Álvarez \& Dagnino, 2001), las movilizaciones pacíficas de 200, 1200, 2000 y 5000 personas de extracción urbana y rural, hechos tales que llevaron a detener el macroproyecto a nivel regional. $\mathrm{Y}$ además las derrotas tanto colectivas y de sus actores en los escenarios del conflicto y a la vez narrar cómo se falla al querer extender la lucha al contexto nacional, es decir, deja como pregunta la falta de articulación de un movimiento social ambientalista a nivel nacional que afronte los conflictos locales y regionales. 


\section{PALABRAS CLAVE}

Movimientos sociales contemporáneos, movimientos ambientalistas en Colombia, conflictos socioambientales, política cultural, sociología de la cultura, audiencia pública ambiental.

\section{"DEFENDERS OF THE WATER MOVEMENT" AT PIEDECUESTA, SANTANDER, COLOMBIA (1995-2005)}

\section{ABSTRACT}

By means of the Action-Participation Research method, the articulation of a local social movement which faced global fights against macro projects for the usurpation of the water resource and fragile ecosystems which were affected because of the extension in the Aqueduct in the Metropolitan area of Bucaramanga, is systematized. The movement has its origins in the area of Piedecuesta (Santander, Colombia), and as a network (Cohen \& Arato, 2000; Melucci, 2002) it has extended to different areas to the municipalities of Guaca, Tona and the Metropolitan Area of Bucaramanga. For this specific case of the "Defenders of the Water Movement" Cohen and Arato's (2000) theories are applied in the reconstruction of civil society using two of the great paradigms of social movements: mobilization of resources and "new social movements", this way, making contemporary social movements easier to understand. The action framework of the "Defenders of the Water Movement" struggle is given in the 1991 Constitution, in which a Social State of Rights immersed into a market economy (Jiménez, 2008 ) is postulated. Thence it follows the legislative flow such as Law 134 of Citizen Participation, which regulates Town Meetings, and Law 99 from 1993 about Environment which, in article 72, refers to Environmental Public Audiences as mechanisms which are used by the Movement above mentioned as struggle instruments. This article allows to glance the role of professionals in the social movement, the dialogue of knowledge between popular knowledge and scientific knowledge which structure the Movement, the role of nongovernmental organizations in the logics of the Neoliberal State (Escobar, Álvarez \& Dagnino, 2001). The creation and evolution of a social movement will be shown, as well as its transformation, its achievements such as the solidarity attained, the I cultural policy generated both within civil society and within the State., The calls to symbolic and counterpublic spaces (Escobar, Álvarez \&Dagnino, 2010), the pacific demonstrations of 200,1200, 2000 and 5000 people from urban and rural origins, facts that made the macro project stop at a regional level. Besides, collective and individual defeats in scenarios of conflict, and also to relate how, wanting to extend the struggle to a national context, fails. This is to say it leaves as a question the lack of articulation of a social environment movement at a national level that faces local and regional environmental conflicts. 


\section{KEY WORDS}

Contemporary social movements, environmental movements in Colombia, social and environmental conflicts, cultural politics, sociology of culture, environmental public audience.

\section{INTRODUCCIÓN}

En este artículo se realiza un análisis de la génesis, desarrollo y ocaso del Movimiento Defensores del Agua, el cual surge como resistencia al Macroproyecto de Ampliación del Acueducto Metropolitano de Bucaramanga -denominado de Piedras Blancas- (Santander, Colombia). Este Movimiento es la expresión de una lucha local de diferentes actores sociales del municipio de Piedecuesta en Santander que se extendió siguiendo la metáfora de la red por toda la provincia de Soto en este mismo departamento. La red ha sido un mecanismo aglutinador de la lucha, en razón de que:

[...] las redes de los movimientos abarcan más que a las organizaciones de movimiento y sus miembros activos; incluye igualmente a los participantes ocasionales en eventos y acciones del movimiento, simpatizantes y colaboradores de ONG's, partidos políticos, universidades, otras instituciones culturales y convencionalmente políticas, la Iglesia y el Estado que por lo menos parcialmente, apoyan las metas de un determinado movimiento y ayudan a desplegar discursos y demandas en contra de instituciones y culturas políticas dominantes (Landim, 1993 citado en Escobar, Álvarez \& Dagnino, 2001, p. 157)

El Movimiento Defensores del Agua se caracterizó en su proceso de lucha por fortalecer su identidad y autonomía e influir sobre la sociedad civil, la sociedad política y, en menos proporción, sobre la sociedad económica en aras de conseguir su objetivo primordial: detener el macroproyecto. Por tanto, el Movimiento de Defensores del Agua se analiza siguiendo lo que se ha denominado la estrategia dual de los movimientos sociales o reconstrucción de la sociedad civil (Cohen \& Arato, 2000).

Este artículo se basa en diferentes fuentes: prensa, la observación participante, la entrevista, archivos gubernamentales y no gubernamentales, que procedieron a triangularse. La observación participante sobre el Movimiento Defensores del Agua de los años 1997 al 2000 ha dado más posibilidad de la crítica de fuentes y, lo más importante, comprensión y minucia en el análisis. Respecto, a la observación participante se anota que: 
La narración que pudiera hacer un participante al término del episodio en el que se haya encontrado implicado únicamente resulta privilegiada en relación con las narraciones de no participantes o de personas posteriores, en la medida que contiene las observaciones de un testigo ocular, es decir, en que tiene un valor documental (Habermas, 1981, p. 187)

En primera instancia se describirá cuáles fueron las causas que dieron origen a la disputa, el segundo apartado mostrará la articulación de las organizaciones sociales de base que fundan el movimiento local de Piedecuesta, destacando principalmente el papel de la Iglesia católica y su defensa por los Derechos Humanos. En el tercer aparte conoceremos cómo fue la influencia de la variable ambiental en este movimiento social. El cuarto apartado se centra en cómo fue el paso de los Cabildos Abiertos populares a los mecanismos institucionalizados de participación ciudadana -el Cabildo Abierto y la Audiencia Pública Ambiental- o acción visible política de los movimientos sociales. Se sigue a un quinto apartado haciendo mención al desarrollo de la variable cultural que se explicitará bajo la acción invisible, las redes y la simbólica que desarrollan los movimientos sociales para luego penetrar en la acción visible de los medios de comunicación. Por último llegaremos al desenlace del Movimiento Defensores del Agua y del macroproyecto.

\section{Génesis de la lucha}

En el Área Metropolitana de Bucaramanga ${ }^{3}-\mathrm{AMB}^{-}$capital del departamento de Santander (Colombia), la Compañía del Acueducto Metropolitano de Bucaramanga -CAMB- encargada del suministro de agua prospectó la Ampliación del Acueducto Metropolitano con base en un argumento hipotético del crecimiento poblacional del AMB al 2025 (hacia 1996 la población aproximada del AMB era de 800.000 habitantes, y se extrapolaban 1'600.000 habitantes para el 2025), lo cual generaría nuevos desarrollos urbanísticos que demandarían agua.

Hacia 1993 se informó por parte del gerente de la CAMB que las instalaciones del acueducto metropolitano tendrían una vida útil hasta el 2010 y se hacía necesario planear una serie de embalses para suplir la demanda de agua potable a partir de este año, y a la vez generar energía (Vanguardia Liberal, 5 de febrero de 1993, p. 3b). Sin embargo, durante una nueva gerencia en la CAMB hacia 1997 se divulgó reiteradamente por los medios de comunicación que si no se ejecutaba la ampliación del acueducto, la ciudad se vería avocada a racionamientos de agua hacia el año 2003.

La CAMB procedió a contratar la elaboración de un proyecto de prefactibilidad y diseños definitivos para la Ampliación del Acueducto Metropolitano de Bucaramanga, que implicaban la construcción de obras civiles como una presa, embalse, túneles 
y trasvases de ríos y quebradas, en zona de páramo y subpáramo de varios municipios, al que se identificó como el Macroproyecto de Piedras Blancas y que se prospectaba como un proyecto de gran magnitud.

El macroproyecto pretendía canalizar las aguas de los ríos Oro, Manco, Lato y Umpalá de Piedecuesta (Santander), construir un embalse de compensación en la confluencia del río Guayabales, las quebradas Piedras Blancas y Antalá, en jurisdicción de los municipios de Silos (Norte de Santander), Guaca, Santa Bárbara y Tona (Santander) con el interés de abastecer los "nuevos desarrollos" del Área Metropolitana de Bucaramanga y a la vez aprovechando las caídas del río de Oro generar electricidad.

En el segundo semestre de 1996 en el municipio de Piedecuesta se presentó un rechazo al macroproyecto, dado que en su jurisdicción se veían involucradas mayor cantidad de fuentes hídricas. Desde esta localidad se lideró por parte del autodenominado Movimiento los Defensores del Agua, conformado por una resistencia civil que llevó a involucrar los demás municipios afectados y habitantes del Área Metropolitana de Bucaramanga.

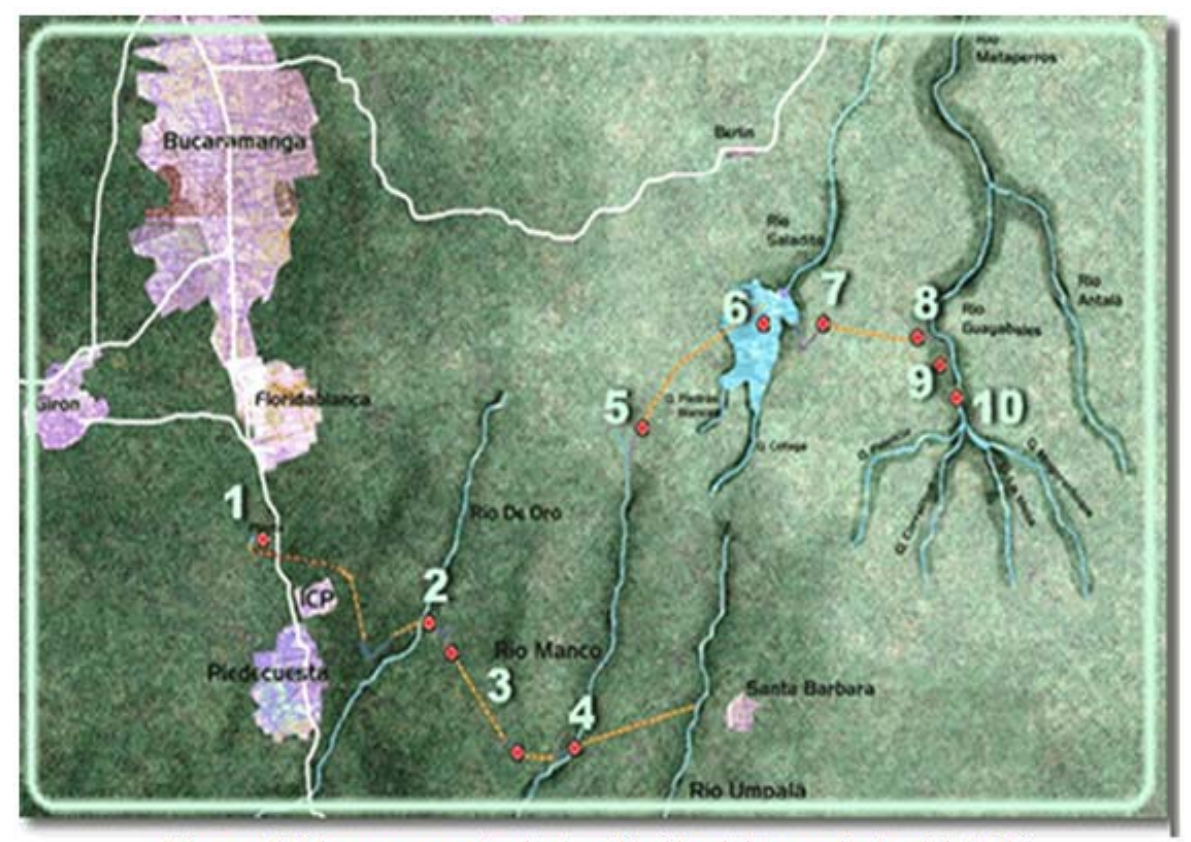

Figura 1. Macroproyecto de Ampliación del Acueducto del AMB Fuente: Vanguardia Liberal, 21 de abril de 1999, p. 3a.

En las demandas de los sectores populares de Piedecuesta se planteaba que más allá de suplir las deficiencias de agua futura con el macroproyecto, subyacía era el interés del gremio constructor del AMB (el gremio constructor estaba representado en las empresas familiares: Hernández Gómez, Marín Valencia, Beltrán Pinzón y Urbanas) por obtener agua para continuar la expansión urbanística hacia los valles de Mensulí, la Vega, Guatiguará y río Frío; considerados por los ambientalistas como 
los pulmones verdes del AMB ya que albergan relictos del árbol de Caracolí.

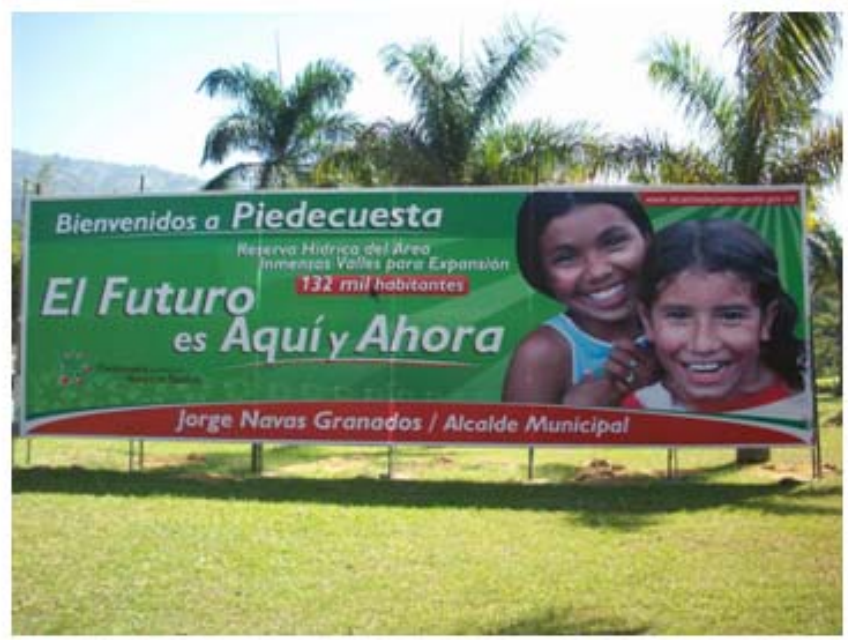

Figura 2. Valla que ilustra la polaridad a que se ve enfrentada la localidad de Piedecuesta, entre el cuidado de sus valles y el desarrollo urbanístico. Fotografia: Tarazona, 2008.

Meses después en el año de 1997 con la incursión de profesionales de diferentes disciplinas al Movimiento Defensores del Agua, se comenzaron a percibir posibles efectos colaterales a la propuesta del macroproyecto como: el desplazamiento de campesinos por la construcción de las futuras obras, impactos en la economía campesina, impactos negativos sobre los bosques de niebla baja y los ecosistemas frágiles de páramo y subpáramo, e impactos geofísicos irreversibles que se veían más propensos por fallas geológicas activas. Todos estos aspectos fueron tomados por los movilizados como "caballo de batalla" dentro de la lucha que se prolongó siete años.

En conclusión, la planeación de técnicos de la CAMB y del gremio constructor sobre el desarrollo futuro imaginado como prioridad para el AMB chocó con la visión de ciudad y región que tenían los habitantes urbanos, rurales, los profesionales y ambientalistas. Estos habitantes se agruparon en el Movimiento Defensores del Agua asumiendo como suya la defensa de la vida, los ríos, los valles, los páramos, su flora y su fauna. Estas visiones en contraste apuntan a que:

La ciudad debe estar en función de quienes existen en ellas y no de lo que se considera funciones prioritarias pese a lo indispensable que puedan ser. Por ende, el planeamiento y el ordenamiento urbano debe llegar a ser objeto de amplias discusiones democráticas (Correa, 1987, p. 6)

A continuación se muestran los orígenes de este proceso del Movimiento Defensores del Agua, presentando la base social, 
las organizaciones que permiten la emergencia del Movimiento, destacando el dinamismo que impregnó la Iglesia católica a través del tema de los derechos humanos y la justicia social.

\section{El papel de la Iglesia católica y los derechos humanos}

En los encuentros del Movimiento Defensores del Agua confluían varias organizaciones sociales del municipio de Piedecuesta que, como nodos, estructuraban una red (Castells, 1999). Hacían parte de esta trama, la Asociación de Juntas de Acción Comunal -ASOJUNTAS-, el Comité Regional de Derechos Humanos, el Consejo Municipal de Desarrollo Rural COMUDE-, la Asociación de Estudiantes de Bachillerato Rural, la Asociación Nacional de Usuarios Campesinos -ANUC-, entre otros; sindicatos de la Salud como Anthoc y la Asociación de Voluntarios de Alivio al Cáncer. Dichas organizaciones de base representativas de diferentes sectores sociales del municipio, compartían y difundían en sus diferentes ámbitos sus impresiones del macroproyecto.

Las tres primeras organizaciones enunciadas eran las más activas dentro del Movimiento, llevaban la batuta en cuanto a convocatorias, encuentros, gestión y la divulgación tanto formal como informal ${ }^{4}$. Se destaca en esta primera etapa del Movimiento el papel jugado por el Comité Regional de Derechos Humanos de la localidad de Piedecuesta que desde su fundación era muy activo en la promoción, el encuentro de las comunidades y la organización social en general.

El Comité Regional de Derechos Humanos fue impulsado por un grupo de mujeres que se organizaron en torno a la labor apostólica de la comunidad Claretiana asentada en la localidad de Piedecuesta. Los Claretianos son unos seguidores de Cristo en la extensión de la palabra, entregados a las comunidades y a la organización social en diferentes lugares del país y del mundo. Baiges Planas los identifica a la vez como una ONG que brinda ayuda al tercer mundo: "Proclade (Promoción Claretiana para el Desarrollo) fija en seis sus campos de trabajo: capacitación agropecuaria, educación, salud, defensa de la justicia y derechos humanos, promoción de la mujer y evangelización" (Baiges, 2001, p. 71).

La localidad de Piedecuesta venía en un proceso de expansión urbanística desde 1980, lo cual generó nuevas problemáticas sociales propiciando que derechos fundamentales de los habitantes de esta población se vieran afectados. En el año 1987 llegaron los Misioneros Claretianos a la localidad de Piedecuesta, quienes con su labor apostólica a través de la conformación de las Comunidades Eclesiales de Base -CEBtoman opción por los más desvalidos en la defensa de la vida, la vivienda digna y los servicios públicos entre otros derechos que se venían vulnerando. El siguiente aparte lo corrobora:

Ante la necesidad de defender sus derechos de vivienda y consecuentemente las condiciones de vida digna, la población intensifica su lucha 
social. Y líderes como la señora Olga López hacen posible coordinar actividades al respecto, pero el contexto político-judicial no deja de influenciar y en medio de las amenazas e intimidaciones por parte de "fuerzas oscuras" es asesinado un hijo de esta ama de casa, líder e integrante de una CEB [...]. En esta lucha popular se hace una manifestación en la que se logra desmovilizar el tráfico de buses en Piedecuesta y como consecuencia se desató fuerte represión. A raíz de esta situación la parroquia asume como compromiso la "opción por la vida" y la "opción por los pobres", por lo cual vino una serie de persecuciones y la siembra del terror a la parroquia que debe replantear su trabajo y asumir la defensa de los derechos humanos como eje de la pastoral (Parroquia Nuestra Señora de la Esperanza, 1998, pp. 4-5)

En 1989, la ola de asesinatos continúa rondando las comunidades que exigen sus derechos. La respuesta de la misión Claretiana en este momento se centra en "la sensibilidad por el trabajo en la promoción y formación de los derechos humanos que se materializa en este año con el acompañamiento que hace la parroquia a varias caminatas, encuentros y cabildos por la vida" (Parroquia Nuestra Señora de la Esperanza, 1998, p. 9). La situación de zozobra se prolonga hasta inicios de la década de 1990, donde la muerte sigue acentuándose de la mano de "fuerzas oscuras" a lo cual las comunidades siguen enarbolando la vida en el marco de la conmemoración de los 500 años de resistencia de la conquista española.

La proclama por la vida trascendió las CEB orientadas en torno a la labor Claretiana del Oriente de Piedecuesta, colonizando diferentes organizaciones e instituciones a través de los medios de comunicación, posicionándose por medio de eucaristías, fiestas, encuentros, caminatas y festivales. El culmen de esta etapa es el "Primer Cabildo Abierto por la Vida" del 3 de noviembre de $1991^{5}$, que dará los primeros pasos de la creación de la ONG, Comité Regional de Derechos Humanos, la cual posteriormente se independiza de la Parroquia Nuestra Señora de la Esperanza sede en Piedecuesta de la comunidad Claretiana. Más adelante algunas integrantes del Comité Regional de Derechos Humanos comienzan a ser estigmatizadas o asociadas con movimientos subversivos por parte de los organismos del Estado, situación que las obliga a salir del país al exilio. El Comité Regional de Derechos Humanos de Piedecuesta termina desintegrándose, por tanto su accionar público se registra aproximadamente de 1991 hasta 1998, tiempo suficiente para incidir en la apertura del Movimiento Defensores del Agua.

El Comité Regional de Derechos Humanos fue un importante eslabón en las primeras etapas del Movimiento Defensores del Agua. Sus líderes fueron las impulsoras, llevaban las memorias, 
escribían, orientaban el cabildeo institucional, mantenían contactos con la prensa local y posibilitaban los encuentros semanales. A raíz de la influencia ejercida por el prestigio y la autoridad del sacerdote Claretiano Héctor Guzmán, comprendían la problemática del agua como efecto de la política neoliberal; a través de su labor apostólica impartía conferencias que eran transversalizadas por temas como la justicia social, la crítica al neoliberalismo y la globalización, que posibilitaron el despertar de conciencias y su movilización.

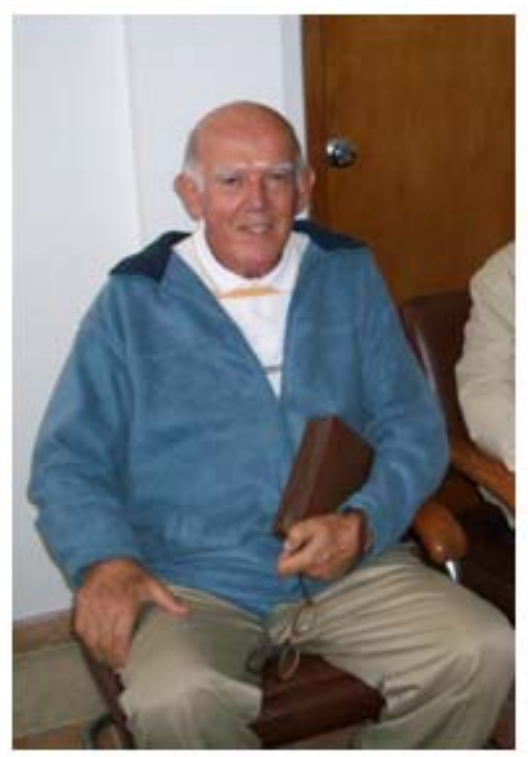
Figura 3. Sacerdote Claretiano Héctor Guzmán.
Fotografia: Tarazona, 2009.

El padre Héctor Guzmán se vinculó a la parroquia Nuestra Señora de la Esperanza hacia el año 1993 cuando comenzaba a debatirse el tema del macroproyecto. Esta parroquia es una de las primeras convocantes del Segundo Cabildo Abierto que se programó en el año 1996, en el que se debatió en particular el tema del agua. Cuando el proceso de movilización en torno a la defensa del agua estaba más avanzado, se vinculó más formalmente la Iglesia católica, designando a un sacerdote de la Diócesis ${ }^{6}$ para este tema en particular. Sin embargo, a título personal el padre Héctor Guzmán siguió al tanto de lo acontecido y participó en un foro en la Universidad Industrial de Santander -UIS- donde manifestó sus argumentos de rechazo al macroproyecto.

Respecto a la participación de la Iglesia católica en este proceso, el testimonio de Fernando Moreno Rojas ${ }^{7}$, es aclaratorio:

Sí, las parroquias intervinieron, el padre Alfonso Reyes, la señora Janeth Vera, la señora Ofelia, don Roberto Camacho. El suscrito desde la Personería Municipal de Piedecuesta, incluso el padre Álvaro también nos ayudó en la convocatoria, la Iglesia, el Episcopado, la 
Corporación de Justicia y Paz (Entrevista con

Fernando Moreno Rojas, 2008)

Habermas ha teorizado sobre la influencia que ejercen diferentes estamentos en los movimientos sociales, reconociendo el papel influyente del prestigio y la "autoridad de eclesiásticos" en los espacios de la opinión pública como agentes que contribuyen a atraer más adherentes a los movimientos sociales (Habermas, 1998, pp. 443-444). Al igual, Martínez Alier hace mención más específicamente para el caso de los movimientos ambientalistas, veamos:

Así estas luchas se inician a menudo con cartas y peticiones a personas con autoridad [...] organizaciones influyentes (como la Iglesia católica en América Latina), como si el mero conocimiento de la injusticia fuera suficiente en sí misma para remediarla (Martínez, 2004, p. 264)

Pero en este caso en particular del Movimiento Defensores del Agua, los sacerdotes han pasado el umbral del simple cruce de cartas, peticiones y conociendo la "injusticia" se hicieron actores fundamentales de los procesos de movilización. Promovieron la organización social con su participación directa, lo que permite que el prestigio, la autoridad de los eclesiásticos se desplieguen tanto en los movimientos como en sus contradictores y en la opinión pública en general que se solidarizan con la causa al ver a los eclesiásticos del lado de los intereses de las comunidades, que son los débiles frente a estos megaproyectos.

El papel de la Iglesia católica en los movimientos sociales es bastante reseñada. Grueso, Rosero y Escobar (2001) en Colombia, ilustran cómo el Proceso de las Comunidades Negras se vio influenciado por el movimiento Golconda, promovido por el Obispo de Buenaventura, Gerardo Valencia Cano -conocido como el "Obispo Rojo"- quien incidió en la conciencia negra, pensamiento actuante hoy, en la Pastoral Afroamericana. En América Latina en respuesta al neoliberalismo, Manuel Castells menciona el papel jugado por la Iglesia en el movimiento Zapatista en México, veamos:

Esas comunidades campesinas, en su mayoría indias, a los que se unieron otros asentamientos de la región de los Altos, no estaban solas en las luchas sociales que habían acometido desde comienzos de la década del setenta. Estaban respaldadas, y hasta cierta medida organizadas, por la Iglesia católica, bajo la iniciativa del Obispo de San Cristóbal de las Casas, Samuel Ruiz, relacionado con la teología de la liberación. Los sacerdotes no solo apoyaban y legitimaban las demandas de los indios sino que los ayudaron a formar cientos de cuadros de los sindicatos campesinos [...]. Más de cien tuhunules (ayudantes de los sacerdotes) y más de mil 
catequistas constituían la espina dorsal del movimiento (Castells, 1999, p. 98)

El Movimiento Defensores del Agua, tenía un encuentro habitual los lunes (día de mercado en la población de Piedecuesta, que permitía la interacción entre líderes rurales y urbanos) donde confluían todos los nodos de la red ${ }^{8}$ para planear la acción estratégica, el boicoteo a un proyecto que se imponía sin su consulta. Hasta aquí podríamos afirmar que se seguía a cabalidad el paradigma de los "nuevos movimientos sociales" que busca el fortalecimiento de la identidad, su aspecto defensivo y la autonomía de la sociedad civil, y el escepticismo o temor al engaño de lo institucional (Cohen \& Arato, 2000). Los teóricos de lo movimientos sociales que han profundizado sobre este tópico advierten que:

\begin{abstract}
Aunque la literatura inicial sobre los movimientos sociales de los años 70 y comienzos de los 80 alababa su rechazo putativo de la política institucional, su defensa de la autonomía absoluta y su énfasis en la democracia directa, muchos análisis recientes sostienen que dichas posturas dieron origen a un "ethos de rechazo indiscriminado de lo institucional" (Doimo, 1993; Silva, 1994; Coelho, 1992; Hellman, 1994) que dificultó a los movimientos la labor de articular de manera eficaz sus exigencias en escenarios políticos formales (Escobar, Álvarez \& Dagnino, 2001, p. 35)
\end{abstract}

Sin embargo, para el caso del Movimiento de Defensores del Agua, la realidad de las organizaciones entremezcladas con parte de la sociedad política colonizó la Personería, la Alcaldía y el Concejo buscando hacerlos sus aliados. Y más allá se buscaba que las instituciones del Estado cumplieran con su función constitucional, buscando una transformación: "[...] este énfasis social no implica, como se afirmó en cierta literatura temprana sobre los movimientos sociales, un rechazo a la institucionalidad política y al Estado, sino más bien una exigencia radical de su transformación" (Dagnino, 2001, p. 71).

Para ese entonces la Personería de Piedecuesta estaba a cargo de Fernando Moreno Rojas, quien tenía un trabajo muy estrecho con las comunidades, especialmente con el Comité Regional de Derechos Humanos y venía siendo puente entre la institucionalidad y se sentía parte de los movimientos locales de Piedecuesta como lo muestra su testimonio:

Recordar que por allá en el año noventa, las fuerzas sociales aquí se organizaron en una asociación que se llamaba Asodefuspi, que era la Asociación de Defensores de los Usuarios de Servicios Públicos. Y a la vez como veníamos de periodos de manos negras, de la cual cuando yo fui inspector de policía, levanté los 
muertos del segundo periodo de la mano negra y veníamos con una presencia pues bastante interesante del ELN en la localidad. Y la Juntas de Acción Comunal, todo el mundo pidiendo como mayor participación, mayor espacio para tratar los problemas que aquejan a la localidad. Entonces cuando yo llego a la Personería pues me desligo de los movimientos a los que pertenecía, el de Derechos Humanos, el de los servicios públicos. Y desde la Personería por ley teníamos que tramitar todo el accionar el Comité de Derechos Humanos y juntamos esfuerzos unos y otros para generar una opinión importante, máxime cuando por esa época era que se estaba tramitando, el robo, el atraco, el fueputa, digamos, el hecho de que nos quitaran las aguas a un pueblo como este para proteger un proyecto metropolitano, un macroproyecto (Entrevista con Fernando Moreno Rojas, 2008)

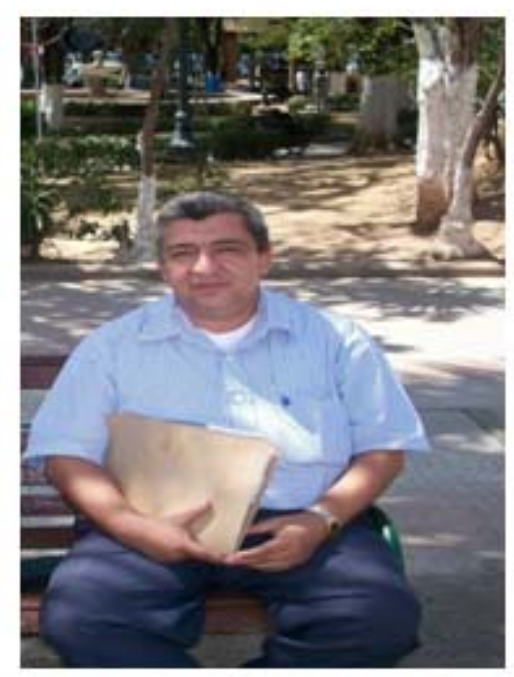

Figura 4. Fernando Moreno Rojas. Fotografia: Tarazona, 2008.

Tanto en la localidad de Piedecuesta como fuera de esta, el Movimiento Defensores del Agua comenzó a ejercer influencia sobre instituciones como las alcaldías, concejos, personerías de los municipios involucrados, la autoridad ambiental, la Asamblea Departamental y la Gobernación. En este sentido el Movimiento Defensores del Agua se puede analizar siguiendo la teoría de la movilización de recursos, donde se conjugan las políticas de ofensiva e influencia sobre la sociedad política, allí se destacan variables como los intereses, los recursos, las oportunidades y las estrategias para explicar la movilización a gran escala (Cohen \& Arato, 2000).

Como se ha señalado, la Iglesia a través de las comunidades eclesiales de base y el Comité Regional de Derechos Humanos son eslabones importantes en la emergencia del Movimiento 
Defensores del Agua. Además se suman como actores preponderantes de la red que se tejió dentro de este movimiento ambientalista. Podemos también destacar por esta descripción que el Movimiento Defensores del Agua no surge en el vacío, hay unas organizaciones precedentes (la ANUC, las JAC, la Iglesia, los sindicatos) que permitieron su apertura. "Las redes de reclutamiento, ningún proceso de movilización comienza en el vacío [...] quienes se movilizan nunca son individuos aislados y desarraigados" (Melucci, 2002, p. 62). Por fortalecer su "política de identidad" y "la política de influencia" tanto en la sociedad civil como en la sociedad política, el Movimiento Defensores del Agua es susceptible de analizarse, a través de lo que Cohen y Arato (2000) denominan el carácter dual de los movimientos sociales.

Una vez conocido el basamento social que permite la emergencia del Movimiento Defensores del Agua es el momento de preguntarnos: ¿Cómo es la convergencia de la variable ambiental de este Movimiento?

De los grupos ecológicos a las organizaciones no gubernamentales ambientalistas -ONGAS-

Con la salida a la luz pública de la intencionalidad de la CAMB de tomar las aguas de Piedecuesta para ampliar el Acueducto Metropolitano de Bucaramanga, las luchas sociales se vincularon a la defensa del agua y la vida, proponiéndose entonces un Segundo Cabildo Abierto el 11 de noviembre de 1996 al que se denominó "Aguas y Vida", en respuesta al megaproyecto. En esta oportunidad se unieron a la lucha nuevas organizaciones sociales del Área Metropolitana de Bucaramanga entre ellas sindicatos y organizaciones no gubernamentales ambientalistas -ONGAS- como: Zua Quetzal, Cabildo Verde de Girón y la Fundación para la Defensa de la Naturaleza. Estas jugaron un papel muy importante en las alternativas que propuso el Cabildo como la de "Conformar la Asociación en Defensa del Agua de Piedecuesta y Realizar una Audiencia Pública Ambiental"’.9 .

Estas ONGAS de reciente formación, la Asociación para la Defensa de los Animales y la Naturaleza-ADAN- en 1988 y el Cabildo Verde de Girón en $1991^{10}$. ONGAS que en sus inicios giraban en torno al liderazgo de Orlando Beltrán Quesada ${ }^{11}$, quien hoy continúa al frente de la primera. Este líder ambientalista había sido influenciado por los primeros grupos ambientales creados en los años ochenta, conozcamos su incursión:

Que me acuerde, yo tampoco tenía ONG, Mauricio Meza nos acompañó, Mauricio Meza, como que Carlitos Eslava con Zua Quetzal [...]. El Cabildo Verde de Girón, nació paralelo con ADAN, o sea, hace 20 años, como al año de haber fundado ADAN [...]. La primera incursión no fue con esto, fue con el Cabildo Verde, porque, yo viví, yo tenía una fábrica en Girón y 
permanecía en Girón cuando fundé ADAN, entonces, cuando surgió la idea del Cabildo Verde, fue porque se celebró el primer Día Mundial de la Tierra [...]. Con Jairo Puente hablamos de celebrar el Día Mundial de la Tierra y con un muchacho ambientalista de la Central Ecológica, que era más antigua que ADAN. Nosotros fuimos los segundos en crear una ONG ambientalista, ya existía la Central Ecológica, llevaba como dos años y el Movimiento Ambientalista del Oriente, que no tenía personería jurídica pero era un movimiento de Jairo Puente [...]. Nos reuníamos alrededor de Jairo para que Jairo nos enseñara, para que Jairo nos orientará, porque él, él, usted sabe ha sido un investigador nato y toda la vida ha leído, le llegaban revistas en francés, mantenía actualizado (Entrevista con Orlando Beltrán Quesada, 2009)

Jairo Puente, es puente entre los grupos llamados en primer momento ecológicos ${ }^{12}$ y las ONGAS de los noventa, fundador del Grupo Ecológico de la UIS ${ }^{13}$ a finales de 1981. El Grupo Ecológico de la UIS, en 1983 realizó una serie de estudios y denuncias sobre la impotabilidad del agua de Barrancabermeja (Santander), lo que ocasionó en dicha ciudad tres paros cívicos en el primer semestre del mismo año. La causante principal de la contaminación del agua era la estatal petrolera ECOPETROL, esta empresa, ante las denuncias del grupo ecológico, decide quejarse ante las directivas de la UIS, lo que obliga al grupo ambientalista a cambiar su nombre por Grupo Ecológico de Santander.

Aunque, el Grupo Ecológico de la UIS ha sido reseñado de manera muy fugaz por actores-narradores de los movimientos ambientales como Ángel Maya, quien menciona que: "hubo algo en la UIS, allí no hubo una personalidad así destacada" (Ángel, 1997, p. 65), muy por el contrario la presente investigación arroja que Jairo Puente es una de las personalidades destacadas que desde la UIS ha ejercido amplia influencia en los movimientos ambientalistas en Santander. Hacia finales de los ochenta este activista aparece como uno de los dinamizadores principales de lo que se llamó el Movimiento Ambientalista del Oriente y que es mencionado en la anterior entrevista por Orlando Beltrán como parte de su inspiración para asumir las luchas de los noventa a través de las ONGAS.

La transmigración es una característica de los movimientos sociales: "la frecuente 'transmigración' de las activistas feministas chilenas, que comúnmente van y vienen entre las ONG y el Estado" (Shild, 1998 citado en Escobar, 1999, p. 160). Para el caso del activismo ambiental, Jairo Puente Brugés, se puede caracterizar como un "transmigrante", quien se desplaza entre el Estado, la academia y las ONGAS. Este activista ambiental en un primer momento laboró con ECOPETROL casi por diez años, luego trabajó con la UIS y la Universidad Santo 
Tomas -USTA- participando en los primeros grupos ecológicos que giraban en torno a las universidades, desde allí entra en activismo ambiental.

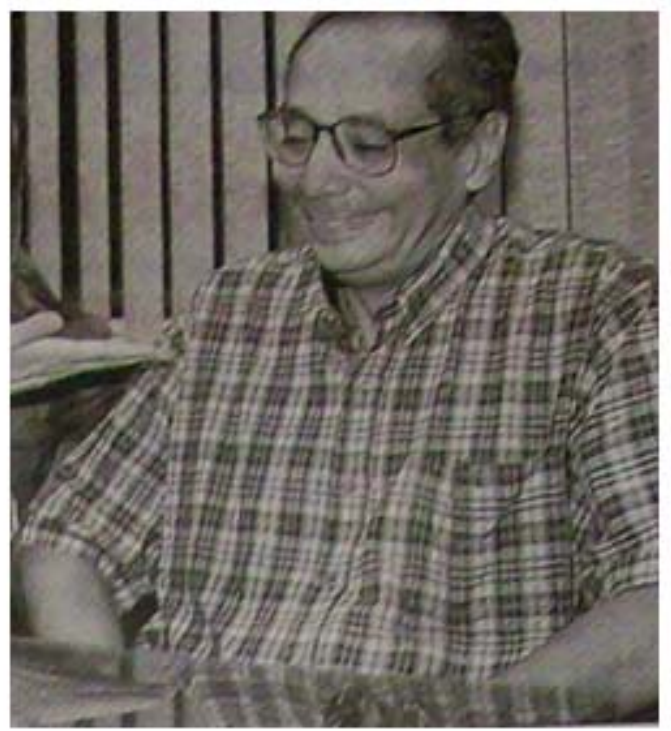

Figura 5. Jairo Puente Brugés.

Fuente: Vanguardia Liberal, 26 de agosto de 2000, p. 1 a.

Trabaja con el INDERENA aproximadamente 10 años en las ciudades de Cartagena, Bucaramanga y Bogotá, formó parte de la desestructuración de esta misma institución (como subgerente de Medio Ambiente) y de la estructuración del Ministerio del Medio Ambiente -MMA-. Retorna a Santander a trabajar con la UIS donde termina pensionándose, al término de esta entrevista ejercía como decano del Programa de Química ambiental de la USTA donde continuaba ejerciendo influencia sobre los movimientos ambientalistas. Desde 1989 ha mantenido su columna en Vanguardia Liberal apoyando luchas puntuales de los movimientos ambientalistas y ejerciendo una actividad pedagógica en temas ambientales.

Se puede evaluar como una transmigración muy propositiva para el movimiento ambientalista en Santander. Al pasar por otros sectores o ámbitos, los activistas de los movimientos sociales conocen mejor las problemáticas y al unísono permean, colonizan e influyen a otros sectores diferentes a la sociedad civil al hacerlos sus aliados o al convencerlos de lo justa de su causa. Jefrey Alexander nos da fuerza a esta idea con el siguiente argumento:

La sociedad civil depende de los recursos, o inputs, de estas otras esferas, de la vida política, de las instituciones económicas, de la amplia discusión cultural, de la organización territorial [...]. La sociedad civil [...] combina estos inputs de acuerdo con la lógica y las demandas de su situación particular (Alexander, 2000, p. 142) 
Al preguntársele por la transmigración, Jairo Puente respondió:

Oye depende del caso, ¿oíste?, porque una de las cosas buenas que hizo Margarita [Marino], fue que ella llegó al INDERENA, contrató mucha gente de las ONG. Pero que eran ambientalistas auténticos y esa gente efectivamente hacía un buen trabajo, toda esa gente que conocí yo allí muchos venían de grupos ambientalistas [...]. Trabajaban porque realmente sentían, ¿oíste?, ellos habían muchos en Parques Nacionales. En el INDERENA lógicamente que hubo casos de corrupción que yo conocí también, pero había mucha gente buena, muy buena, perfectamente comprometida (Entrevista con Jairo Puente, 2009)

Los historiadores de los movimientos ambientales en Colombia han registrado la transmigración de los trabajadores del Inderena (Ruiz, 1997; Hernández \& Villegas, 2003; Tobasura, 2004). "Quizá la labor más importante del Inderena en sus 25 años de vida fue la formación de 'líderes ambientales'. Buena parte de los ambientalistas del país han pasado por la 'Escuela del Inderena"' (Tobasura, 2004, p. 129).

Otro grupo que tiene amplia incidencia en Santander para aquella época es la Corporación Ecológica y Cultural Yarigüies, su nombre hace alusión al ecosistema que defendía. Su causa primordial era convertir la Serranía de los Cobardes o Cordillera de los Yarigüies (ramal oriental de los Andes) en un parque natural, idea que venían impulsando desde los años ochenta, y que hasta 1992 comienza a tener eco en las autoridades de los municipios asentados en la Serranía; "para determinar como reserva forestal protectora 140 mil hectáreas de la parte alta de la Serranía de los Yarigüies, se reúnen hoy los doce alcaldes residentes en la zona, quienes expresaron preocupación por el alto grado de deforestación que se registra en el lugar" (Vanguardia Liberal, 5 de noviembre de 1992, p. 4c). La sede principal de la Corporación se localizaba en la población de San Vicente de Chucurí, liderada por Enrique Moncayo ${ }^{14}$ y los hermanos Ardila $^{15}$. Esta Corporación ha venido siendo reseñada por los historiadores del movimiento ambiental, veamos:

El decenio de los ochentas [...] surgen, pues, una serie de organizaciones al calor del furor que a nivel nacional está despertando el tema ambiental y de la irradiación que desde el centro-occidente se está haciendo. Mayda, Penca de Sábila, Bacatá, Natura, Fescol, Manzanares, Yarigüies, Grupo Ecológico del Cauca, Herencia Verde, son algunas de las organizaciones que saltan a la palestra (Álvarez, 1997, p. 33)

Hoy todavía el proyecto central del Grupo Yarigüies, del gran parque o reserva, continúa siendo una quimera. Más bien, por el contrario, otros proyectos no muy "santos" rondan la Serranía de los Cobardes: 
Grandes multinacionales del carbón como Riotinto y Centromin iniciaron la explotación en El Carmen, proyectan hacerlo en Landázuri y exploran de pé a pá el resto de la serranía que es, en realidad, una gran mina que yace en las entrañas de los Cobardes (Molano, El Espectador, 14 de septiembre de 2008, p. 53)

Existieron otros grupos pioneros en los movimientos ambientales en Santander que quedan sin reseñar, lo importante es destacar que mantuvieron enlaces con el llamado "movimiento ambientalista nacional en construcción" a través del vínculo o red que se estableció a través de un órgano informativo, el SOS, como se narra a continuación:

Hubo un grupo que fue muy importante en los años ochenta que fue el grupo ecológico del Tolima. Que allá estaba este Palomino, Gonzalo Palomino ese era famoso en esa época, o sea, yo creo que a nivel nacional los pioneros fueron ellos y cuando nosotros creamos el grupo acá en Santander nos basamos mucho en ellos, más o menos fue con base en la experiencia de Palomino [...]. Porque ellos nos mandaban boletines, ellos tenían un boletín buenísimo, el SOS [...]. Y fuimos a eventos conjuntos y todo, ¿oíste' [...] y nosotros fue un poco siguiéndoles los pasos a ellos y ellos nos mandaban el boletín, e hicimos encuentros con ellos. Palomino estuvo aquí una vez, pero hace 25, 24 años creo, y nosotros fuimos allá también, y nosotros en esa época nos comunicábamos bastante con ellos, es que además había encuentros nacionales y entonces allá nos veíamos, también con otra gente (Entrevista con Jairo Puente, 2009)

Lo anterior nos confirma al igual como se evidenció en el caso de los Grupos Ambientales en la Universidad de Nariño [ver: "Movimiento en Defensa del Lago de la Cocha, Pasto, Nariño (1993-2001)", artículo publicado en el No. 30 de la Revista Luna Azul, 2010], la convergencia del Movimiento Ambientalista Colombiano en los ochenta alrededor del SOS Ecológico. Gonzalo Palomino comenta:

Salía en Ibagué con un formato original, con un color amarillo horrible que lo hacía más original, con una forma de doblarlo muy fácil y así se echaba al correo y finalmente llegó en un momento en que el tema era muy apetecido (Palomino, 1997, p. 116)

Los grupos ecológicos de los años ochenta son parte de la inspiración de las ONGAS de los años noventa, notemos:

[...] las luchas sociales de los años 80 dejaron un importante legado para las de los 90: crearon espacios públicos informales, discontinuos y plurales en los cuales pueden circular diversas exigencias y en los cuales puede tener lugar el reconocimiento de otros como portadores de derechos (Paolly \& Telles, 
2001 citados en Escobar, Álvarez \& Dagnino, 2001, p. 43)

De esta manera, las ONGAS fueron creciendo, reuniéndose en las sedes de sus organizaciones. Sin embargo, con la convocatoria que se desata a partir de la Ley 99/93 para nombrar en los Consejos Directivos de las Corporaciones Autónomas Regionales -CAR- a miembros de las ONGAS, se estructura lo que es la Mesa Ambiental de la Provincia de Soto $^{16}$ (colectivo de ONGAS, organizaciones de base donde se debatían temas ambientales y se planificaban luchas en torno a problemáticas ambientales). Este colectivo ocupará por un lapso el espacio del auditorio de la Corporación de Defensa de la Meseta de Bucaramanga -CDMB- para sus encuentros semanales, tiempo durante el cual el tema del macroproyecto transverzaliza la Mesa y el Movimiento Defensores del Agua acrecienta su radio de acción, convoca y aglutina al movimiento ambientalista de la región al hacer frente a los megaproyectos ${ }^{17}$. Este se puede definir el momento culmen del movimiento ambientalista en la provincia de Soto en Santander al crear este espacio de concertación entre sociedad civil y Estado.

Es de resaltar que como representante de las ONGAS ante el Consejo Directivo de la CDMB se eligió a Orlando Beltrán Quesada que, coherente con su papel, representó a cabalidad los intereses del ambientalismo en la jurisdicción. Ello coadyuvó a hacer más fuerte la lucha del Movimiento Defensores del Agua en la reivindicación de sus derechos a la información, la participación, la decisión, y a estrechar los vínculos entre sociedad civil y Estado.

Posteriormente la mesa ambiental de la provincia de Soto termina desintegrándose y algunas ONGAS vuelven a encontrarse en torno a sus sedes y otras ONGAS continúan en la sede de la CDMB. Los que salen se podrían definir como dentro de la tendencia del ambientalismo popular y son quienes continúan con las convocatorias previas a la Audiencia Pública Ambiental del macroproyecto de Ampliación del Acueducto Metropolitano de Bucaramanga. Tobasura sobre el ambientalismo popular hace mención así:

Esta corriente [...] [sus] luchas sociales son entendidas como luchas ecológicas, luchas urbanas populares pero sobre todo luchas campesinas [...]. Se encuentran entre estos movimientos los ecologistas que tratan de sacar los recursos naturales de la economía de mercado y de la racionalidad mercantil (Tobasura, 2004, p. 57)

Para el ambientalismo popular las ONGAS que permanecen en la sede de la CDMB su "principal característica radica en ser profesionales y empresarios de subsistencia de la gestión ambiental, a quienes cada vez les importa menos lo ambiental como movimiento social"18. 
Toda la anterior descripción del paso de los grupos ambientales a las ONGAS nos muestra el aglutinamiento a la red del Movimiento Defensores del Agua de las primeras ONGAS del AMB. Aparecen los nombres de líderes del movimiento ambientalista en Santander y se ilustra la transmigración de uno de sus líderes más destacados. A la vez surge el enlace entre los grupos ambientales en Santander con el "movimiento nacional ambientalista en construcción" a través del SOS [como una constante que ya se destacó en el "Movimiento en Defensa del Lago de la Cocha, Pasto, Nariño (1993-2001)", ver: artículo publicado en el No. 30 de la Revista Luna Azul, 2010]. Se detecta el surgimiento de la Mesa Ambiental de la provincia de Soto como una instancia de concertación entre sociedad civil y Estado que fortalece el Movimiento Defensores del Agua, y a la vez se muestra su declive que trae la división de dos sectores de ONGAS, el ambientalismo popular y los "mercaderes del ambientalismo". El ambientalismo popular continúa en el debate del macroproyecto, para ese momento en las convocatorias al Cabildo Abierto local y a la Audiencia Pública Ambiental.

\section{Cabildo abierto}

Los cabildos abiertos convocados en torno a las Comunidades Eclesiales de Base impulsadas por los Claretianos y el Comité Regional de Derechos Humanos eran de iniciativa popular. A partir de las alianzas del Movimiento Defensores del Agua con parte de la institucionalidad, se comienzan a utilizar los espacios de participación ciudadana avalados por la Constitución de 1991 y reglamentados en la Ley 99/93 del Medio Ambiente Art. 72 sobre las Audiencias Públicas Ambientales, y la Ley 134 de Participación Ciudadana Art. 8189 sobre los Cabildos Abiertos, mecanismos estos de participación ciudadana que se utilizaron como estrategia de lucha.

Evelina Dagnino enuncia este paso, entre lo popular y lo institucional, como la nueva ciudadanía de los años 90 y además menciona cómo:

[...] no es contradictorio hacer énfasis en estas experiencias de intervención popular en el Estado [...]. Estas experiencias muestran cambios no sólo en las modalidades de la toma de decisiones dentro del Estado, sino también entre las relaciones del Estado y la sociedad (Dagnino, 2001, pp. 77-78)

La alianza de las organizaciones de base de Piedecuesta con las ONGAS a través de la "política de influencia", la cual va dirigida a las estructuras económicas y el Estado y hace ofensivos $^{19}$ a los movimientos sociales (Cohen \& Arato, 2000), obtiene un primer resultado: persuadieron a la Personería de Piedecuesta a que exigiera a la Corporación de Defensa de la Meseta de Bucaramanga -CDMB- la convocatoria a una Audiencia Pública Ambiental -APA-, para discutir las afectaciones del macroproyecto. 
Es entonces la conjugación del Movimiento de Defensores del Agua con la institucionalidad para hacer frente al macroproyecto, lo que prospecta la concreción de Convocar el 4 de agosto de 1997 al Cabildo Abierto (Ley 134 de 1994, tramitado por el Consejo Municipal), mecanismo de participación que estaba sin estrenar en muchos municipios colombianos (Gutiérrez, 1998) y que con la presión del Movimiento Defensores del Agua se hizo utilizar. En este espacio las comunidades exigieron la devolución de la administración del Acueducto local de Piedecuesta que estaba en manos de la CAMB desde 1990. A la vez, al sentir vulnerados sus derechos con el macroproyecto los participantes reaccionan y desde el saber natural campesino-popular se presentan argumentos a su favor que parecen increíbles al saber científico-técnico ${ }^{20}$. Pero, ¿cómo se expresa el saber popular?

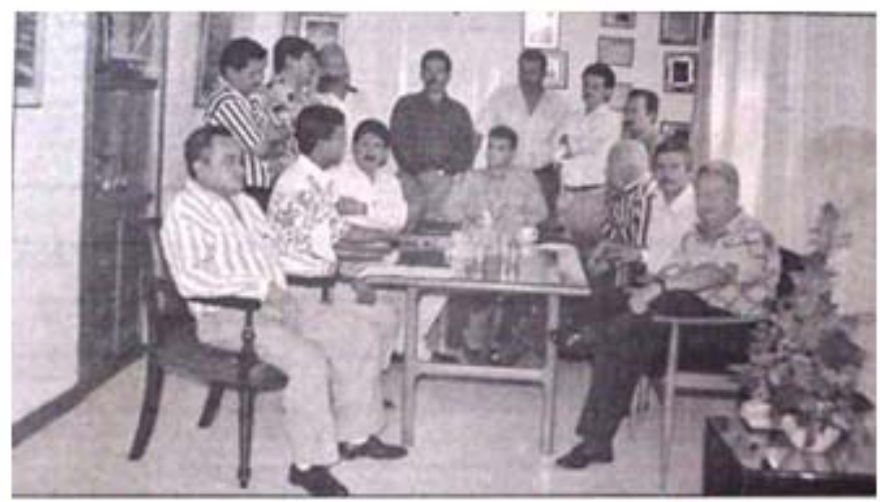

Figura 6. Integrantes del Concejo local de Piedecuesta. Fuente: Vanguardia Liberal, 1998.

Obviamente, hay dificultades reales para que los sectores populares jueguen este nuevo papel. La mayoría de ellas tienen que ver con desigualdades en términos de información, usos del lenguaje y conocimiento técnico. Sin embargo, estas dificultades no están sirviendo como excusa para eliminar el nuevo papel de los sectores populares; más bien, en prácticas concretas, están siendo enfrentadas (Dagnino, 2001, p. 78)

Aunque en lo práctico estos cabildos abiertos vienen siendo criticados por no ser definitorios de las temáticas abordadas, el mecanismo de participación bien orientado entre sociedad civil y Estado, y que surja de los intereses de la voluntad de las comunidades, posibilita el debate y sus conclusiones aportan argumentos a los encargados de tomar las decisiones. Además, este mecanismo de participación: "[...] contribuye a la creación de espacios públicos, en los cuales los intereses, especificidades y diferencias privados y comunes pueden ser expuestos y ser materia de discusión y negociación" (Telles \& Paoli, 2001 citados en Dagnino, 2001, p. 78). 
Estos espacios públicos generados en torno a los cabildos abiertos permitieron a los movilizados preparar el terreno y foguearse para buscar contundencia en la Audiencia Pública Ambiental, que pasaremos a describir a continuación.

\section{Audiencia pública ambiental -APA-}

Luego de solicitada la APA, el Movimiento Defensores del Agua influencia la sociedad política de Piedecuesta, y logra a través de la Personería del municipio que la CDMB orientara una charla a los líderes locales del Movimiento y la comunidad en general, sobre Mecanismos de Participación Ciudadana en lo Ambiental, especialmente sobre la APA. La CDMB permanecía muy alejada de las comunidades en lo referente a propagar los derechos de los ciudadanos en la defensa de los recursos naturales. Además, la percepción de los movilizados sobre la CDMB es que favorecía los intereses del gremio constructor ${ }^{21} y$ se le veía con un amplio favoritismo al megaproyecto, como se percibió a futuro con el dilatamiento en la definición del trámite de la licencia ambiental.

Pero esta espera en el trámite de la licencia Ambiental al macroproyecto, fortaleció al Movimiento y fue un punto a favor para hacer más críticas sobre la parcialidad de la CDMB a favor de la CAMB y los gremios de la construcción. Consolidándose un trabajo al interior tanto de la sociedad civil, de la sociedad política y de la sociedad económica, más allá de la localidad de Piedecuesta, avanzando hacia la zona de influencia del macroproyecto, donde la prioridad consistía en la persuasión sobre los efectos adversos de la realización de este. Se utilizaron diferentes escenarios y espacios públicos ${ }^{22}$ : colegios, universidades, alcaldías, personerías y concejos de municipios involucrados, juntas de acción comunal urbanas y rurales, sindicatos, organizaciones campesinas, grupos de caminantes, organizaciones gubernamentales ${ }^{23}$ y no gubernamentales.

De esta política de ofensiva, la administración de Piedecuesta convocó a una Asamblea sobre el Agua un mes antes de la APA, en lo que se podría llamar una Preaudiencia Ambiental. El encuentro convocó a las administraciones, personerías de los municipios involucrados, sus comunidades y las ONGAS quienes acordaron a futuro actuar en forma conjunta en la negativa al macroproyecto.

Esta Preaudiencia Ambiental realizada en Piedecuesta el 30 de enero de 1999, se tituló "Asamblea Comunitaria de la Defensa del Agua", de allí se creó un Comité Interistitucional Prodefensa de los Recursos Hídricos próximo a la Audiencia Pública Ambiental, conformado por las personerías de los municipios de Tona, Piedecuesta y el Concejo y la Iglesia, además de otras organizaciones sociales y las ONGAS ${ }^{24}$. Esto acrecentó la red que se tejía en torno al Movimiento Defensores del Agua, estos eventos visibles atraen más adeptos a los movimientos ${ }^{25}$. Como entendemos la visibilidad de los movimientos: 
La visibilidad refuerza las redes inmersas, proporciona energía para renovar la solidaridad, facilita la creación de nuevos grupos y el reclutamiento de nuevos militantes atraídos por la movilización pública que ya fluyen en la red inmersa (Melucci, 2002, p. 74)

El Comité Interistitucional comenzó a hacer exigencias puntuales tanto a la alcaldías locales como a la CDMB. A esta última se le solicitó que la APA se realizara en la localidad de Piedecuesta por ser el municipio de más impacto ambiental del macroproyecto, y de más cercanía para los habitantes campesinos, petición que fue negada por la autoridad ambiental.

La APA se convocó según Auto No. 006 de enero 26 de 1999, realizándose el 17 de febrero de 1999 en el Auditorio de la Universidad Autónoma de Bucaramanga ${ }^{26}$. Haciéndose ruptura en los procesos de APA en el departamento de Santander con la participación de 1200 personas y con 65 ponencias inscritas ${ }^{27}$. Todas las ponencias no se pudieron presentar en el transcurso del día, y las comunidades allí reunidas en cabeza de los peticionarios que eran los miembros de las ONGAS, exigieron a la CDMB que el próximo sitio de encuentro fuera en la localidad de Piedecuesta el día 22 de abril de 1997 en conmemoración del Día Mundial de la Tierra.

También, ya se mostró cómo la convocatoria a la conformación del Cabildo Verde se realizó en conmemoración de una fecha ambientalista. Tobasura (2004) ha reseñado la celebración de efemérides como uno de los elementos que crea identidad en los movimientos ambientalistas. Por tanto, lugar y fecha de la segunda sesión de la audiencia fueron aprobadas por la autoridad ambiental a consecuencia del desplazamiento pacífico de muchos campesinos que se convirtió en un testimonio de su lucha por la Defensa del Agua y de los ecosistemas de páramo.

Luego del éxito de la primera fase de la APA, para la segunda fase el geólogo Onécimo Caviedes $^{28}$ del Movimiento Defensores del Agua avanza en la colonización de la Universidad Pública, la UIS. Allí se realizan tres foros ${ }^{29}$, el más importante a mencionar el 12 de abril de 1999 en el auditorio mayor de este claustro con la asistencia de 100 personas. La confluencia de diferentes escenarios y grupos sociales ha sido teorizada, notemos:

En escenarios públicos diversos se han elaborado y debatido políticas alternativas relacionadas con [...] medio ambiente y el desarrollo sostenible. Estos asuntos han encendido debates en diferentes foros que involucran sindicatos, movimientos de bases, asociaciones de barrio, ONG, organizaciones de apoyo técnico, profesionales liberales y universidades (Paoli \& Telles, 2001, p. 96) 
La sensibilización lograda en la UIS generó que, en la APA del 22 de abril de 1999 en Piedecuesta convocada en el Coliseo de Villa Concha, se destacara por la presencia masiva de estudiantes que con arengas y mucho jolgorio apoyaron a las comunidades urbanas y rurales de los municipios afectados por el macroproyecto. La unión de campesinos, estudiantes y habitantes urbanos consolidó la asistencia de 2000 personas. Las arengas y la confrontación contra las pocas ponencias a favor del macroproyecto hicieron que la autoridad ambiental convocara a la próxima sesión de la APA nuevamente en la ciudad de Bucaramanga, negando de tajo la participación de los mayores involucrados, los campesinos.

La "política de inclusión" se dirige a las instituciones políticas para obtener reconocimiento para nuevos actores políticos como miembros de la sociedad política y para lograr beneficios para aquellos que los representan haciendo ofensivos a los movimientos sociales (Cohen \& Arato, 2000). La puesta en marcha de la "política de inclusión" por parte del Movimiento Defensores del Agua, permite que uno de sus fundadores, José del Rosario Gutiérrez ${ }^{30}$, acceda como segundo renglón en el Consejo local de Piedecuesta. Este líder en el periodo que le correspondió sesionar generó una amplia discusión en torno a la relación del Plan de Ordenamiento Territorial (Ley 388/1997) y el macroproyecto ${ }^{31}$. Durante estos dos meses el Movimiento continúa el cabildeo a nivel regional y nacional; en vísperas de la última sesión de la APA se visitan las zonas de páramo de afectación del macroproyecto. Así mismo, asisten a la convocatoria hecha por el alcalde de Tona en el corregimiento de Berlín el 17 de julio de 1999.

La última sesión de la APA se convocó en el Colegio Salesiano de Bucaramanga, el 22 de julio de 1999. Donde se evidenció un desgaste en las movilizaciones y se denunció cómo los campesinos que venían del municipio de Tona fueron detenidos por grupos militares en el kilómetro 18, entrando a la ciudad de Bucaramanga. A la vez esta sesión se caracterizó por la participación del sindicato de la CAMB, que entró gritando arengas al recinto de la APA en torno a los efectos sociales del macroproyecto, dado que la CAMB pasaba a capital privado y extranjero.

Luego de culminadas las sesiones de la APA, el vínculo con el sindicato de la CAMB posibilita que ciertos líderes de las ONGAS lleven el debate del macroproyecto al paro cívico del 31 de agosto de 1999, situación que es aprovechada por la CAMB para promover unas mesas de concertación luego de la férrea oposición del Movimiento Defensores del Agua al megaproyecto en la APA. Dichas mesas fueron criticadas en el Movimiento, pues se argumentaba que con la APA ya se había recopilado el acervo probatorio suficiente, siendo inútil su discusión posterior. 


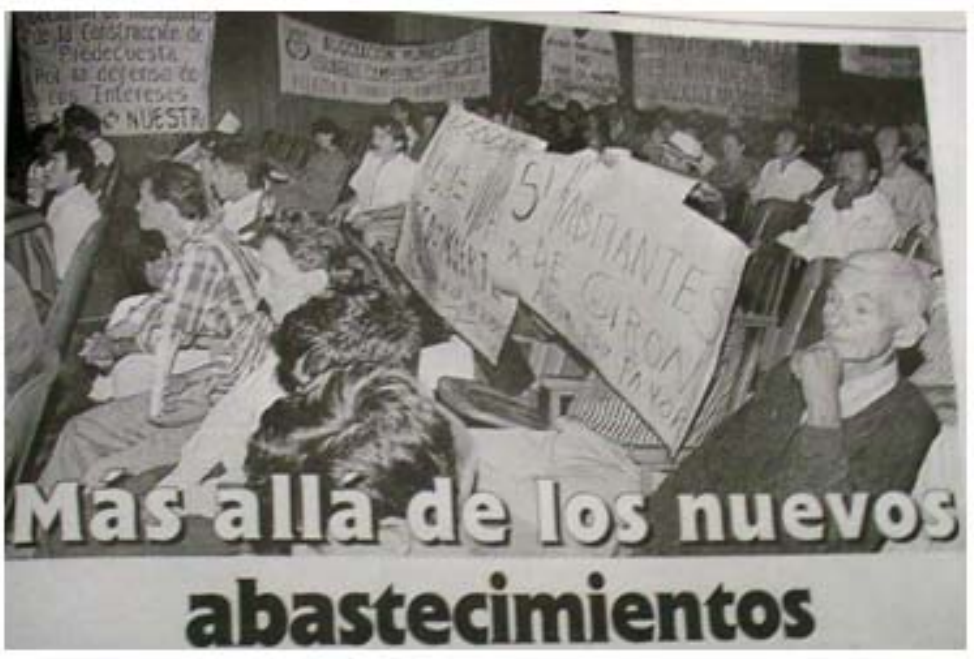

Figura 7. Última sesión de la Audiencia Pública Ambiental. Fuente: Vanguardia Liberal (Dominical), 13 de mayo de 2001, p. 8.

Lo que se evidencia con las arengas del sindicato ${ }^{32}$ de la CAMB en la última fase de la APA y con las mesas de concertación posteriores a la Audiencia Pública Ambiental, al estilo de las reivindicaciones de los heredados en el movimiento obrero, así:

[...] como sucede siempre en la historia de los movimientos, los nuevos actores [en este caso los movimientos ambientalistas] se expresan con el viejo lenguaje porque todavía no tienen uno propio. Mientras se forma, utilizamos el que heredamos de los movimientos que le preceden, y que tiene sus raíces en la memoria y en los símbolos del pasado (Melucci, 2002, p. 78)

El Cabildo Abierto, la Asamblea del Agua, los foros y principalmente la APA en sus tres fases, demuestran la ampliación de la democracia a partir de la resistencia de un movimiento ambientalista local a los megaproyectos. Para el caso particular

del Movimiento de Defensores del Agua, fueron las organizaciones de base en primera instancia, partidos políticos, la Iglesia, las ONGAS, organizaciones gubernamentales, universidad y sindicatos elementos cruciales para extender y hacer conocer sus demandas. Se ha evidenciado cómo a través de la visibilidad los movimientos sociales contemporáneos extienden sus redes y aumentan sus adeptos o militantes, mostramos:

[...] en torno a estos movimientos se desarrolla una red asociativa amplia, multifacética y descentralizada, la cual articulaba asociaciones de base, grupos de apoyo técnico, organizaciones no gubernamentales (ONG), 
Iglesias, profesionales liberales, sindicatos e incluso universidades. Álvarez hace énfasis en el hecho de que en esta red conformada por escenarios públicos plurales y heterogéneos se produjo una multiplicidad de nuevos asuntos y exigencias éticas de ciudadanía los cuales atraviesan grupos sociales, instituciones, organizaciones y partidos, y se traducen en una capacidad, inesperada en muchos casos para articular y movilizar actores colectivos (Álvarez, 2001 citado en Paoli \& Telles, 2001, p. 92)

Es por medio del paso de los cabildos abiertos populares a los mecanismos institucionalizados de participación como se logra que los conflictos ambientales locales se puedan resolver de manera pacífica, canalizando el descontento social de movimientos sociales. Además que dichos espacios de participación hacen visible la protesta llamando la atención de los medios masivos de comunicación a través de las redes invisibles de los movimientos sociales que es el tema que abordaremos a continuación. La solicitud de esta primera APA sobre el macroproyecto, dio pie para que otros proyectos polémicos del AMB, fueran también objeto de $A_{P A}{ }^{33}$ y sus licencias fueron tramitadas rápidamente, en contraste del precedente de la licencia ambiental del macroproyecto que permitió la organización y unidad de los movimientos ambientales en la provincia de Soto (Santander).

\section{El papel de los medios de comunicación, de la acción invisible a la visible}

Por su historia, los movimientos ambientales han tenido amplia recepción en los medios de comunicación formal. Las primeras denuncias del Grupo Ecológico de la UIS o después Grupo Ecológico Santander, se registraron en el diario regional Vanguardia Liberal, como se evidencia en el siguiente testimonio:

Entonces empezamos a hacer algunas denuncias en Vanguardia, porque yo me conocí en esa época, entonces con Silvia Galvis, que era la encargada en ese momento de la unidad de investigación de Vanguardia Liberal. Entonces a ella le interesó mucho el tema, entonces empezó a publicar vainas sobre el tema ambiental [...] y ahí nos ayudó mucho Vanguardia, porque Vanguardia efectivamente nos publicaba los comunicados nuestros. Y Silvia por su parte sacaba sus propios informes, ya sobre ella me acuerdo del caso de Barranca [recordar la impotabilidad del agua], me acuerdo también sobre pesticidas químicos y ella sacaba era unos informes de página entera, eso nos ayudó mucho a darnos a conocer en Santander (Entrevista con Jairo Puente, 2009) 
Al igual, como se ha registrado en la actual descripción del Movimiento Defensores del Agua, este permite abordarse a través de los registros de los medios de comunicación, el siguiente argumento es ilustrativo: "Los sucesos son el resultado 'objetivizado' (especialmente cuando las fuentes son informes de prensa y grabaciones públicas) de una fábrica de relaciones y significados, de un proceso interactivo que es la base de la acción visible" (Melucci, 2002, p. 60).

Es por tanto esta trama de relaciones y significados o acción invisible latente del Movimiento Defensores del Agua, que alude específicamente a lo cultural de los movimientos sociales, la que permite ser reconocidos por la acción visible de los debates públicos y los medios de comunicación. Eventos e instancias suscitados también con base en la comunicación informal de las redes y los medios alternativos que utilizan los movimientos sociales.

Para convocar a la APA, el Movimiento de Defensores del Agua utilizó el perifoneo con el apoyo logístico de la institucionalidad de Piedecuesta. Las redes comunitarias posibilitan el llamado por alta voz, en la zona rural y urbana ${ }^{34}$, que utilizando un lenguaje popular a través de coplas, consignas, y música campesina invitan y persuaden a las comunidades a asistir a la APA.

También se envían sendas cartas de invitación directa a participar en la APA a los líderes de organizaciones sociales rurales y urbanas, especialmente a los directivos de las JAC. Al aplicar estas estrategias, los movimientos sociales contemporáneos manejan formas de comunicación que buscan atraer más adherentes a su causa, para que se sientan directamente involucrados. Surge aquí la idea de "reconocimiento" de Hegel ${ }^{35}$, de tener en cuenta al otro, de la otredad, como un elemento fundamental de la comunicación acción que se manifiesta ante la exclusión y el sometimiento de la cultura política tradicional que hace un uso instrumental del otro. Los movimientos sociales a través de este tipo de acciones invisibles son incluyentes y posibilitan la construcción de la democracia.

Es en el evento de la APA, donde las redes del Movimiento Defensores del Agua en la localidad de Piedecuesta permiten vincular a la movilización al grupo cultural de Zanqueros de Pidecuesta, que de una manera festiva animan el certamen democrático. El grupo de Zanqueros, perteneciente a la institución oficial de Bellas Artes del municipio, también se encargó de elaborar emotivas pancartas alusivas a la defensa de las aguas. Allí es importante destacar cómo un líder de esta institución participaba de la Red y del encuentro habitual de los lunes del Movimiento.

Luego de la APA, el Movimiento Defensores del Agua obtiene más visibilidad y reconocimiento vinculándose a la red de miembros de grupos de teatro. Estos artistas permiten una respuesta contundente, a un intento de la autoridad ambiental, 
por coordinar una veeduría (Comité de Vigilancia a la Gestión Ambiental -CIVIGEP-) al macroproyecto, sin haber definido aún la obtención de la licencia ambiental. Se preparó en compañía de miembros de la mesa ambiental una obra de teatro como forma de protesta el 21 de julio de 2000 día de instalación del CIVIGEP a las entradas del recinto de la CDMB, la cual atrae a los medios de comunicación. A la vez, otro grupo de activistas en el recinto expresaba de manera argumentada lo inconveniente del CIVIGEP, y además, miembros del sindicalismo expresaban unas arengas muy fuertes contra la institucionalidad ambiental en pleno, que se encontraba en el recinto, lo que trae el fracaso de la instalación del CIVIGEP y es un triunfo más para el Movimiento Defensores del Agua que torpedea el intento de la autoridad por querer imponer el macroproyecto. En las memorias del Movimiento Defensores del Agua este suceso se registra así:

Joaquín Beltrán trata de revivir una participación amañada, invitando unas tres ONG y desconociendo las administraciones municipales de los sectores involucrados, lo cual es criticado en este evento. Se hace una protesta simbólica que atrae a los medios de comunicación y tuvimos alta receptividad, no se logró firmar la conformación del CIVIGEP (Asociación de defensores de las aguas del páramo de Berlín y los municipios dependientes de sus recursos naturales, Acta \# 0093 del 15 de enero de 2001)

Esta protesta mezcló lo local, lo nacional y expresó el malestar que se palpaba en el momento en torno a los megaproyectos en el país. Al siguiente día de la protesta, el diario regional destacó la movilización con imágenes de la obra teatral (Vanguardia Liberal, 22 de julio de 2000, p. 1). Son estas acciones espectaculares y coloridas (mimos, zanqueros, teatro) utilizadas por los movimientos ambientales, las que atraen a los medios de comunicación. "No es accidental que el uso de lenguajes expresivos, teatro, video e imágenes de varios tipos constituya una de las prácticas centrales de las tramas cotidianas de los movimientos contemporáneos" (Melucci, 2002, p. 165).

Es la acción simbólica o latente de los movimientos ambientales, lo que permite la construcción de redes que impactan y generan controversia en la opinión pública llamando la atención de los medios masivos. Más allá de la amistad generada con los medios en algunos movimientos sociales subyace un trabajo en red que es el que se manifiesta en el caso del Movimiento Defensores del Agua.

La empatía del Movimiento de Defensores del Agua con los corresponsales de los medios en general, se debía a que sus denuncias se basaban en ilustraciones sobre los territorios que se verían impactados, recreando su riqueza social y natural. Tal acción, creaba un sentido de pertenencia en un contexto de conurbación donde se añora el paisaje rural, el cual es evocado por los migrantes que reaccionaban en la defensa ante la amenaza de su destrucción. Por lo tanto, los corresponsales 
veían en los integrantes del Movimiento unos mensajeros, portadores de datos o información relevante. Los teóricos de los movimientos sociales contemporáneos, enuncian cómo los movimientos en sí son unos mensajeros, "actúan como nuevos medios de comunicación, es decir, alumbran a lo que todo sistema oculta de sí mismo, el grado de silencio, violencia e irracionalidad siempre velado en los códigos dominantes" (Melucci, 2002, p. 103).

El Movimiento Defensores del Agua se caracterizó, particularmente en el inicio, transcurso y final de su contienda por enfrentar a sus contradictores a través de los medios de comunicación.

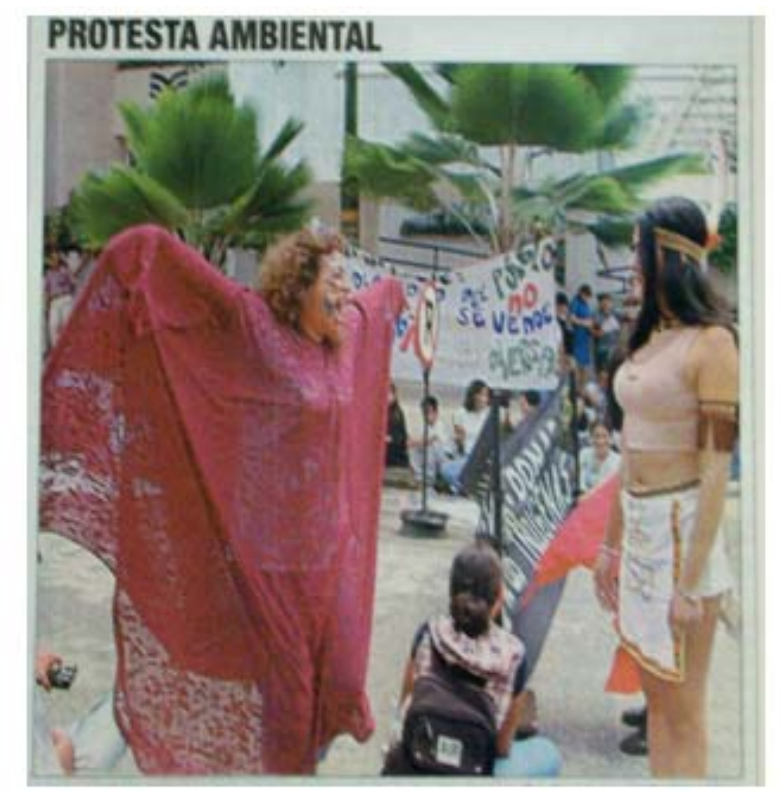

Figura 8. Registro en prensa local de movilización ambiental en contra del macroproyecto.

Fuente: Vanguardia Liberal, 22 de julio de 2000, p. 1.

Los autores en los análisis de marcos de los movimientos sociales, critican esta postura y dicen: "para complicar aun más las cosas, estas batallas no se librarán cara a cara, sino de forma indirecta, a través de los filtros de los medios de comunicación" (McAdam, McCarthy \& Zald, 1999, p. 41).

En el caso del Movimiento Defensores del Agua, muchas de sus batallas se dieron a través de la radio y la prensa escrita local. Esta oportunidad de poder obtener una audiencia, trajo el avance, la colonización de la sociedad civil, la sociedad política y la confusión de sus contradictores como la CAMB y las intrigas generadas en los constructores o sociedad económica. En los boletines de prensa del Movimiento de Defensores del Agua, se acertaba, se denunciaba y se ilustraba e informaba a la población en general sobre las riquezas de los páramos de los bosques de niebla baja y sobre la flora y la fauna que se impactaría. 
Los cara a cara se presentaron en los cabildos abiertos, en la APA y en unas reuniones de socialización del macroproyecto que la CAMB impartió en abril de 1997 en las veredas de los municipios afectados (dichas reuniones fueron torpedeadas por los activistas). A excepción de estos espacios mencionados, el debate se ejerció en los medios de comunicación.

Además, la CAMB al no tener desde el inicio del megaproyecto una estrategia de participación los distanció de las comunidades, de igual manera el Movimiento se había encargado de vetarlos como los "afectadores" polarizando las opiniones sobre el macroproyecto. Las partes no se podían, ni querían ver cara a cara, la única manera de conocer de su contradictor era a través de los medios de comunicación. Así se comenzó a generar pánico en los medios de comunicación por parte de la CAMB intimidando con la idea de que si no se construía el macroproyecto la ciudad comenzaría a sufrir racionamientos de agua a partir de 2003. Los representantes de los gremios hacían eco de los informes de la CAMB, por lo tanto, el debate consistía en una lucha, en que el último informe publicado en la prensa por las partes del conflicto (en un polo el Movimiento Defensores del Agua y en el otro la CAMB o el gremio de los constructores) quedaba en las mentes de los lectores.

Según la argumentación e información divulgada por las partes se tenía la sensación de que quien hacia la última entrega al medio de comunicación, dependiendo de su impacto, golpeaba a su enemigo e iba "triunfando" en la contienda.

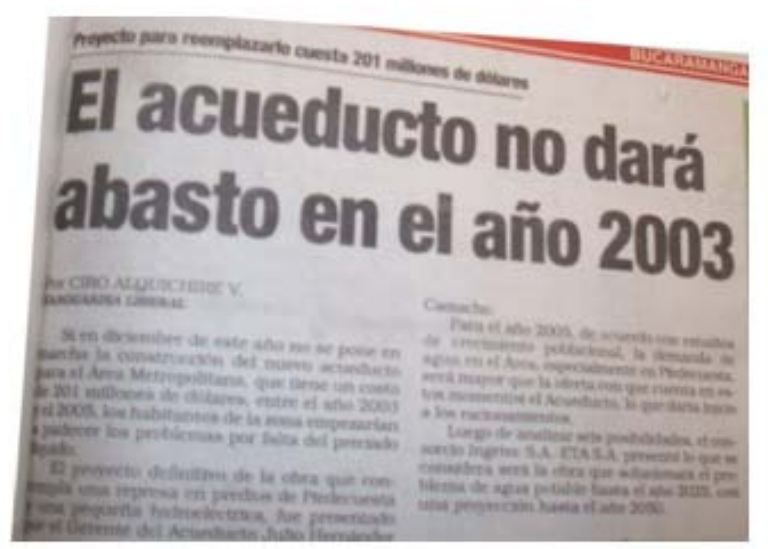

Figura 9. Campaña emprendida por la CAMB en los medios para presionar la construcción del megaproyecto.

Fuente: Vanguardia Liberal, 17 de marzo de 1997, p. 1.

Para el caso del Movimiento Defensores del Agua, y de acuerdo con la revisión sistemática de la prensa, Vanguardia Liberal para los años 1993 al 2003, aparecen aproximadamente cien registros respecto a la controversia suscitada en torno a la Defensa del Agua de Piedecuesta. Como ha reseñado Manuel Castells, el movimiento ecologista a nivel mundial ha tenido mayor adaptabilidad al paradigma informacional de nuestro 
tiempo a través de los medios de comunicación. Permitiendo ampliar sus convocatorias y movilizaciones por redes tanto a nivel global como local, en razón de que los movimientos ambientalistas crean:

Acontecimientos que llamen la atención de los medios [...] además, la presencia constante de temas medioambientales en los medios ha prestado una legitimidad mayor que cualquier otra causa [...] la acción espectacular que ejercen, el autosacrificio [como es el caso de Chico Mendes] [...]; plantea los problemas sistémicos de un modo más vigoroso que cualquier discurso ideológico tradicional. Con frecuencia, los propios ecologistas alimentan a los medios con imágenes preciosas que dicen más que un informe (Castells, 1999, pp. 153-154)

En síntesis, el Movimiento Defensores del Agua a través de su acción latente o invisible atrajo a los medios de comunicación. Su empatía con el diario Vanguardia Liberal, se ha debido, entre otras razones, a estructuras de oportunidad aprovechadas por el Movimiento, al trabajo en red que permitió mostrarse, y a la vez, a la acogida que suscitan las temáticas ambientales como de candente actualidad.

A la vez, la CAMB y la sociedad económica también optaron por divulgar a través de los medios de comunicación sus pasos en torno al proceso de licenciamiento del macroproyecto, debido al rechazo que suscitó el mismo y a no tener una estrategia social para llegar con el macroproyecto a las comunidades impactadas.

Aunque el tema de la radio no se explora en este estudio, es importante destacar que también fue un canal que se utilizó con bastante frecuencia por líderes del Movimiento de Defensores del Agua en particular por las redes locales de Piedecuesta, quienes por su tradición oral eran más afines a este espacio. A continuación mostraremos el ocaso del Movimiento Defensores del Agua y el desenlace del macroproyecto que se enmarca entre lo local, lo nacional y que tendrá la voz de los diferentes actores involucrados en esta contienda.

\section{Entre lo local y lo nacional}

La acción visible e invisible de las redes, la movilización pacífica y más allá la política de influencia y colonización sobre la autoridad ambiental por parte del Movimiento al igual que sobre la sociedad civil, obligó a la Corporación de Defensa de la Meseta de Bucaramanga -CDMB-, a negar la licencia ambiental al macroproyecto (según Resolución No. 0137 de febrero 26 de 2001) decisión que asumió el nuevo gerente de la CDMB, Fredy Anaya.

El Movimiento Defensores del Agua logró detener el macroproyecto a nivel local. El argumento sobre la expansión urbana del Área Metropolitana de Bucaramanga hacia Sabana de Torres Santander (Arenas, 2001) había permeado a la 
CDMB, como se demuestra a partir de la entrevista con su anterior gerente Joaquín Beltrán ${ }^{36}$, quien enuncia:

Entonces, se les estaba proponiendo que en lugar de hacer crecer aquí a Bucaramanga, que Bucaramanga no tiene mucha actividad [...] pensemos irnos para un lado más productivo, para Sabana de Torres o para un sitio, donde la tierra no sea tan buena, pero sí sirva para urbanizar y donde haya más movimiento y se generen otras actividades económicas que generen crecimiento (Entrevista con Joaquín Beltrán, 2009)

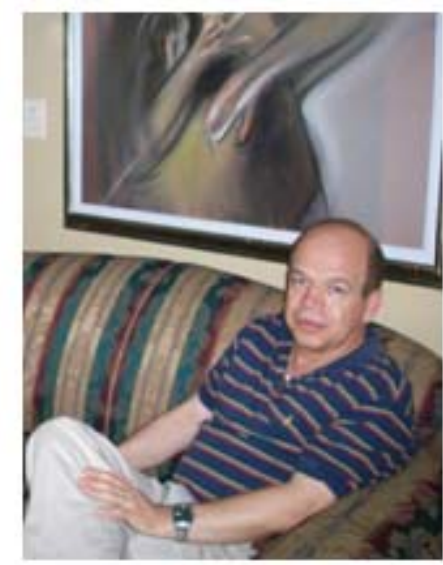

Figura 10. Joaquín Beltrán. Fotografia: Tarazona, 2008.

Aunque el auto de negación de licencia no enunciaba este aspecto, este testimonio anterior demuestra como el exgerente de la CDMB que había vivido todo el proceso, desde la solicitud de licencia por la CAMB, terminó haciendo eco de uno de las hipótesis propuestas por Emilio Arenas sobre la migración poblacional. El Movimiento Defensores del Agua reseñaba el triunfo
obtenido así:

Celebramos la sensata decisión del director de la CDMB, que se convierte en la firme decisión que muchos campesinos y habitantes urbanos tomaron en el transcurso de este proceso que arrancó en 1996. Este es el triunfo de todos los habitantes de los rincones de nuestros páramos, desde Santa Bárbara, Piedecuesta, Tona, Silos, Guaca, que se afianzaron en su propuesta y supieron salir al llamado de ciudadanos conscientes de los irreversibles impactos ambientales, sociales, económicos y culturales del macroproyecto del Acueducto Metropolitano de Bucaramanga (Vanguardia Liberal, 28 de febrero de 2001, p. 1, 3a)

Es decir, la lucha a nivel regional se ganó, mas la CAMB apeló ante el entonces Ministerio del Medio Ambiente -MMA-. En palabras del ingeniero de la CAMB Álvaro Prada ${ }^{37}$, argumenta: 
Digamos el movimiento local, localmente pesa mucho la protesta social. Entonces la autoridad ambiental local, lo pensaba mucho al tomar esas decisiones porque tenía la presión local [...]. Como institución dijeron, no, toca, es negar la licencia porque se nos viene es el pueblo encima. Nosotros, por eso hicimos la reclamación, el recurso de reposición ante el Ministerio, entonces a nivel de Ministerio en Bogotá ya no hay tanta presión local y ellos sí analizaron el proyecto y dijeron esto no es tan grave como se había presentado, o sea se miró el Plan de Manejo, todas las retribuciones que había para la comunidad (Entrevista con Álvaro Prada, 2009)

La licencia se obtuvo según Resolución 0960 expedida el 9 de septiembre de 2003 por el ya Ministerio de Ambiente, Vivienda y Desarrollo Territorial -MAVDT-. Hay varios precedentes en el país en que pese a que las CAR expidan conceptos negativos a megaproyectos, el MAVDT termina dando las licencias generando gran controversia en sus decisiones.

En el MAVDT el proyecto se quedó sin la presencia del Movimiento Defensores del Agua, la distancia entre Bogotá y Bucaramanga es de $379 \mathrm{~km}$, no habían redes a nivel central que ejercieran puja ante el Ministerio como sí se evidenció en el caso de la Defensa del lago de la Cocha (artículo publicado en el No. 30 de la revista Luna Azul). Como ha teorizado Martínez Alier "la distancia geográfica y social de los centros de poder, muchas veces dificulta el acceso y cabildeo directos" (Martínez, 2004, p. 264). A partir de una entrevista mediada por el gerente de la CDMB de la época, entre Juan Mayr Maldonado de visita a Bucaramanga y activistas del Movimiento, se narra así lo sucedido por uno de los activistas, quien dice:

El ministro manifestó [...] Piedecuesta no tiene dolientes, ya lleva muchos meses el expediente en el Ministerio y ninguna persona de Piedecuesta ha indagado sobre el tema. En cambio la CAMB y la Sociedad de Ingenieros tienen un equipo de abogados que permanentemente están solicitando información del caso en el Ministerio. El ministro igualmente nos manifestó que como estaban las cosas, él estaba a punto de salir, pues el 7 de agosto terminaba el periodo de Andrés Pastrana, que él no iba a firmar ninguna resolución aprobando la licencia ambiental. Ese día se acordó que la administración municipal contrataría abogados para que se encargaran de presentar los alegatos correspondientes en el ministerio. Pero el señor alcalde [Fernando Moreno Rojas] $y$ el señor gerente [Oscar Jaimes] de la Piedecuestana [Empresa Prestadora de Servicios Públicos] quedaron encargados de realizar la labor, pasó el tiempo y siempre la 
administración en cabeza del alcalde manifestaba que lo acordado en aquel momento se estaba realizando. $Y$ que ellos mismos alcalde y gerente de Piedecuestana estaban viajando al Ministerio del Medio Ambiente para informarse del tema (Entrevista con José del Rosario Gutiérrez, 2005)

El Movimiento Defensores del Agua nunca pudo responder contundentemente al otorgamiento de licencia ambiental por parte del MAVDT. Hubo intentos locales como el que manifiesta José del Rosario Gutiérrez, sin embargo no hubo una estrategia que obligara a las administraciones a ejercer el cabildeo a nivel central, de esta manera las autoridades fácilmente no encararon el problema evadiendo su responsabilidad; veamos el relato del alcalde del momento al respecto:

Realmente estuve pendiente en el Ministerio del Medio Ambiente, traté de contratar unos abogados expertos en derecho administrativo y en esta parte ambiental sobre lo del agua, pero se acabó el periodo [...]. El movimiento social estuvo hasta el momento [...] en que la Corporación niega la licencia y después en Bogotá, pues le cambiaron la versión a la solicitud de concesión de las aguas del río, otorgando la licencia. Entonces ya la cuestión deja de ser social y se mete en el plano jurídico, ya tocaría demandar ante el Tribunal Administrativo de Cundinamarca, la nulidad de esa licencia. Situación que creo que hasta el momento nadie ha interesado, pero yo si estuve interesado en mi época, pero desgraciadamente se nos acabó el tiempo (Entrevista con Fernando Moreno Rojas, 2008)

Para este momento el Movimiento Defensores del Agua estaba en vías de desintegración, en razón de que se había creado con un objetivo fundamental: confrontar el macroproyecto a nivel local. Luego de obtenido este objetivo hacia el año 2001 con la negación al macroproyecto a nivel regional, el Movimiento entró en un descenso de sus gestiones que lo llevó a su extinción, como se ha teorizado sobre los movimientos, así: "Más difícil es hablar de movimientos como sujetos relativamente estables de acción colectiva, en el caso de formas de movilización bastante más fugaces o definidas principalmente por el objetivo. Este es el caso de la movilización ecológica" (Melucci, 2002, p. 80).

Los profesionales del Movimiento Defensores del Agua no ejercieron las demandas legales, se habían retirado a otros asuntos propios como manutención y al mismo ejercicio de sus profesiones. El Movimiento, por medio de la influencia obtenida sobre las administraciones locales, recibía de estas los dineros básicos de la movilización. El hecho de que el Movimiento Defensores del Agua no extendiera redes a nivel central, en Bogotá, se debe en parte a una particularidad de este Movimiento que lo confinó a la región. Pese a ejercer influencia a nivel nacional en varios eventos, nunca se obtuvo una comunicación fluida y directa en Bogotá con miembros de los que se denomina el "Movimiento Ambiental en Construcción". Censat Agua Viva, impulsora del movimiento ambientalista en 
Santander y con sede principal en Bogotá, conocía del Movimiento. No obstante, no se crearon solidaridades plenas, pues había precedentes de desconfianzas y disparidades ideológicas que se habían originado desde la creación del Ecofondo. Hubo una desarticulación entre el movimiento ambientalista local y el nacional que se puede comprender a partir de lo teorizado acerca de los movimientos sociales:

El compromiso hacia el localismo explica
quizás, la razón por la cual en muchos de los
ensayos parecen presuponerse las metas de
trabajar por cambios leves y la imposibilidad de
confrontar el sistema de manera general. Es de
esta manera que se vive el sistema. Sólo las
condiciones locales dan referentes para
términos como igualdad, explotación, ganancia
de poder y democracia. Esto no equivale a
decir que el pensamiento radical o la
imaginación utópica son imposibles (Pratt,
2001, p. 441)

Las luchas locales han sido una constante en los movimientos ambientalistas colombianos y a la vez generan controversia con quienes quieren un movimiento homogéneo, integrado, superestructurado, con unas directrices centrales acorde con los paradigmas de las movilizaciones de otrora.

La movilización local del Movimiento Defensores del Agua no fue en vano. La no obtención fácil y rápida de la licencia ambiental atrasó el proceso llevado por la CAMB, y dio la razón a los movilizados sobre la versión de que la ampliación del acueducto de Bucaramanga se sobredimensionó creando un macroproyecto, el cual hoy, pese a tener licencia ambiental de construcción del MAVDT, fue revaluado por la banca internacional por su imposible apoyo financiero. La CAMB tuvo que recurrir a buscar otras fuentes hídricas alternativas las cuales se alejaron de la localidad de Piedecuesta, sin embargo prevalece la idea de construir un embalse sobre el río Tona. Veamos:

El proyecto de Piedras Blancas, casualmente era hacer un embalse en el páramo de Berlín y trasvasarlo a las cuencas del Manco y del Oro y hacia un trasvase del Umpalá, entonces ese lo iniciamos en el 95. Entonces, en el 2003 nos otorgaron la licencia ambiental, a partir del 2003 se contrató a través del BID la estructuración técnica y financiera del proyecto. Entonces, bueno, tenemos ese gran proyecto para ejecutarlo, entonces los estructuradores financieros ellos sí, sí analizan como cualquier banca de inversión que analiza la capacidad de endeudamiento de la empresa [...] el proyecto [evaluado] en 280 millones de dólares. Y la banca de inversión pues nos evaluó a nosotros y nosotros actualmente tenemos una capacidad 
de endeudamiento de hasta 100 millones de dólares, entonces no teníamos capacidad de endeudamiento. Entonces, la recomendación de los estructuradores financieros fue buscar un proyecto paralelo y que fuéramos capaces de financiarlo [...]. Entonces nos tocó reactivar un proyecto que teníamos a nivel de prefactibilidad que era regular el río Tona en la parte baja. Entonces la regulación nos daba 1000 litros, 1100 litros por segundo, su costo es alrededor de 100 millones de dólares, entonces los estructuradores financieros le dieron viabilidad al proyecto a corto plazo. El proyecto de regulación del Tona bajo que hoy denominamos embalse de Bucaramanga (Entrevista con Álvaro Prada, 2009)

El embalse sobre el río Tona, viene siendo motivo de preocupación de algunos ambientalistas de la región como Jairo Puente:

Tengo mis dudas sobre el embalse, porque de acuerdo con la Comisión Mundial de Embalses, antes de decidir hacer proyectos es necesario realizar una evaluación de otras posibilidades. Es decir, en una ciudad como Bucaramanga puede ser de mayor ayuda empezar a implementar un programa de ahorro y si se limpian las aguas, ¿todavía sería necesario construir el embalse? Estudios realizados en otras ciudades que implementaron el sistema de embalse, han demostrado que esas grandes presas son las responsables de un alto grado de gases invernadero (Vanguardia Liberal, 23 de Mayo de 2008, p. 1b )

Este capítulo mostró el surgimiento y consolidación del Movimiento Defensores del Agua al lograr colonizar la institucionalidad y posicionar sus propuestas en la CDMB. La CDMB por su trayectoria y cercanía con la CAMB, planificaban un desarrollo urbanístico del Área Metropolitana de Bucaramanga. La primera a través del alcantarillado y la segunda con los suministros de agua. Sin embargo, el discurso del Movimiento permeó a su antiguo exgerente quien por más de quince años desde esta visión ingenieril dirigió esta entidad.

Se destacó cómo el Movimiento Defensores del Agua dio la lucha a nivel local logrando detener el macroproyecto, sin poder colonizar ni obtener influencia en el ámbito central-nacional. Sus redes no lograron empatar con las del Movimiento Ambientalista Nacional, por desconfianzas creadas en torno a la fundación del Ecofondo; pareciera ser que, como lo ilustra Pratt (2001), solo en lo local se hace factible combatir el sistema.

Se describió el declive del Movimiento Defensores del Agua, que una vez realizado su objetivo se extinguió, lo que se ha 
denominado la fugacidad de los movimientos ambientales. Los movimientos sociales nacen, crecen, dan sus frutos y mueren. Se percibió el reconocimiento por parte de los contradictores del Movimiento de su fuerza local y cómo su persistencia atrasó el megaproyecto.

Se pudo llegar al desenlace del megaproyecto que tuvo como facilidad de parte del Estado la anuencia de la nueva administración de Álvaro Uribe Vélez para su licenciamiento. Sin embargo, por estar sobredimensionado no fue viable financieramente comprobándose lo innecesario de este tipo de obras; cosa, que fue denunciada por el Movimiento Defensores del Agua en su momento, y que se convierte en un común denominador de los megaproyectos. La pregunta sería: ¿Cuánto costó a los contribuyentes todo el proceso de licenciamiento?

El megaproyecto está en "remojo" y hacia futuro puede revivirse, como lo narra el actual director del Proyecto Embalse de Bucaramanga:

Pero, Piedras Blancas quedó en diseño y quedó para futuro, entonces a futuro cuando hayamos crecido más, y tengamos más capacidad de endeudamiento lo podemos ejecutar, pero entonces ya quedó al largo plazo, porque tenemos los diseños definitivos, tenemos la licencia ambiental, nos faltaba era el dinero (Entrevista con Álvaro Prada, 2009)

Igual expectativa mantienen los movilizados, con la esperanzas de combatirlo: "Pero pienso yo, que la comunidad ahorita debe organizarse en aras de buscar un decaimiento de ese acto administrativo por la no aplicación, por la no ejecución" (Entrevista con Fernando Moreno Rojas, 2008). Añadiríamos por último, cómo a través de esta narración-evaluación realizada sobre el Movimiento Defensores del Agua, se pueden inspirar nuevas luchas en la perspectiva de sepultar definitivamente el macroproyecto.

\section{Red Movimiento Defensores del Agua}

Se ha visto cómo el Movimiento Defensores del Agua se estructura a partir de una red que va creciendo y extendiéndose con base en el modelo de la latencia y la visibilidad (Melucci, 2002). Es decir, la latencia, hace alusión a lo cultural, a las redes invisibles, a toda la trama subyacente que permite la movilización. La visibilidad, es lo político, las salidas a la luz pública de los movimientos en los escenarios de los medios de comunicación.

En primera instancia a la Red del Movimiento, se suman agentes como la Iglesia católica, los Defensores de Derechos Humanos, los sindicatos, las ONG, las personerías y alcaldías de los municipios, los partidos, las universidades, los profesionales, organizaciones de base. En este sentido, 
Dagnino (2001) alude la noción de campo ético/político como la articulación en diferentes movimientos sociales con otros sectores y organizaciones, y que para el caso del Movimiento Defensores del Agua le permite crear solidaridad para hacer más fuerte su lucha.

El movimiento local de Defensores del Agua a través de la "política de identidad", "la política de influencia e inclusión" sobre la sociedad civil, la sociedad política y la sociedad económica (Cohen \& Arato, 2000) logra su objetivo primordial: detener el macroproyecto. Aunque la influencia ejercida sobre la sociedad económica fue menos evidente, permitió canalizar el conflicto ambiental de manera pacífica entre estos actores antagónicos. Como anotan los teóricos: "Debemos admitir que es difícil aplicar la misma concepción a la sociedad económica, donde las condiciones de posibilidad y por tanto las posibilidades de democratización están incluso más restringidas" (Cohen \& Arato, 2000, p. 553).

En el año 2003 la ciudad de Bucaramanga no sufrió racionamientos de agua, según alarma establecida en los medios de comunicación por la CAMB y el gremio constructor con el interés de generar una opinión favorable en la búsqueda de la licencia ambiental por parte de la CDMB. Sin embargo, en 2008-2009 se persistió en aplicar la misma estrategia, en los medios de comunicación, para obtener la aprobación del Proyecto Embalse de Bucaramanga ${ }^{38}$.

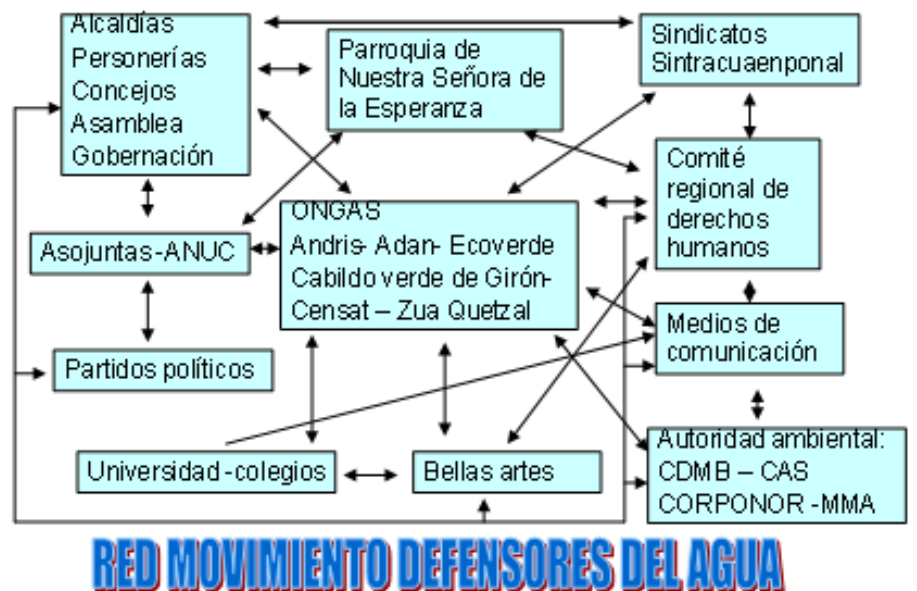

Figura 11. Red del Movimiento en Defensa del Agua de Piedecuesta y municipios vecinos.

El Movimiento Defensores del Agua también articuló su lucha a través del diario regional más importante del oriente colombiano, Vanguardia Liberal. Valiéndose de las oportunidades, redes comunitarias, los medios alternativos y la dramaturgia que atrajeron a los medios de comunicación masiva, notándose que:

[...] estos movimientos sociales [...] pueden a su vez dramatizar sus contribuciones y 
escenificarlas de forma tan eficaz que los medios de comunicación de masas se den por enterados de la cosa. Sólo a través de su tratamiento y discusión en los medios de comunicación de masas alcanzan esos temas el gran público y logran penetrar en la agenda pública (Habermas, 1998, p. 463)

Para penetrar la agenda pública o la acción visible, el Movimiento Defensores del Agua partió de los cabildos abiertos de carácter popular y utilizó también mecanismos institucionalizados de participación ciudadana como los Cabildos Abiertos (Ley 134 de 1994) y la Audiencia Pública Ambiental (Ley 99/93). Estas acciones que crearon solidaridad, extendieron su radio de acción y trajeron más adherentes al Movimiento, como se concreta en el repertorio los movimientos sociales:

En algunos casos, los movimientos sociales no sólo han tenido éxito en traducir sus agendas a políticas públicas y en expandir las fronteras de la política institucional, sino que también han luchado por redefinir los sentidos de las nociones convencionales de ciudadanía, representación política, participación y en consecuencia de la democracia (Álvarez \& Dagnino, 1999, p. 134)

Se ve cómo la luchas populares de los ochenta dieron fundamento al Movimiento Defensores del Agua en los noventa. "Durante los decenios de los setenta y los ochenta, las luchas cívicas [...] estaban relacionadas con servicios públicos domiciliarios y sociales, y protección de los derechos humanos y ampliaciones democráticas (García, 2001, p. 97). Y para el caso de Barrancabermeja las luchas populares se mezclaron con los nacientes movimientos ambientalistas.

Para el Movimiento Defensores del Agua, se describió cómo en la última sesión de la APA y en la Post-Audiencia, el Sindicato de la CAMB utilizó mesas de concertación, un mecanismo propio de la organización sindical, aplicado a las luchas ambientales. Este mecanismo fue rechazado por el movimiento ambientalista, en razón de que los recursos naturales no son negociables. Con esta postura se demuestra cómo los movimientos sociales contemporáneos adoptan posturas de identidad propias de su carácter.

Las ONGAS en el caso de la provincia de Soto en Santander confluyeron en la Mesa Ambiental, donde se gestó un espacio de concertación entre Estado y sociedad civil, sin embargo el proceso se dislocó en dos tendencias, los del Ambientalismo Popular y los "mercaderes del ambientalismo". Los primeros se vincularon directamente a la resistencia del macroproyecto.

Pero más allá de pérdidas y ganancias con el otorgamiento por parte del MAVDT de la licencia al macroproyecto, el Movimiento 
Defensores del Agua ganó, al crear solidaridad, al fortalecer la democracia dentro de la sociedad civil y del Estado, al darle nuevos significados a las luchas contra el neoliberalismo a nivel local. Como se ha venido argumentando: "Los movimientos también generan nuevas solidaridades, alteran la estructura asociativa de la sociedad civil y crean una pluralidad de nuevos espacios públicos, a la vez que amplían y revitalizan los espacios que ya están institucionalizados" (Cohen \& Arato, 2000, p. 592).

Con la licencia ambiental del MAVDT para el macroproyecto, pero sin la financiación del BID, se corrobora lo ya teorizado por Carlos Castro en estudio del agua en el Valle de México:

La manutención y expansión de los acueductos -sistemas hidráulicos- es que se constituyen en una hipoteca para las generaciones futuras, debido al requerimiento cada vez de mayores inversiones para mantener los sistemas funcionando y para su eventual expansión, mantenimiento y mejoramiento, en vista de un número supuesto creciente de usuarios (Conferencia de Castro José E., 1998)

La CAMB venía pagando un empréstito por el bombeo de agua de la planta de Bosconia que surtía a Bucaramanga desde el año 1996. El megaproyecto se presupuestó en 280 millones de dólares y se prospectó en vista de que posiblemente al 2025 van a vivir 1'600.0000 habitantes en el Área Metropolitana de Bucaramanga. En solo sus estudios se implicó un elevado costo $^{39}$. Al igual, sucede con el actual Proyecto Embalse de Bucaramanga que está evaluado en 100 millones de dólares, los cuales el BID financiará a la CAMB por poseer esta capacidad de endeudamiento. En conclusión, todos estos dineros que son empréstitos de la banca multilateral, por vía de tarifas terminan siendo costeados por los usuarios.

El Movimiento Defensores del Agua cumplió un ciclo luego de que su objetivo principal fuera correspondido. Nació de una inquietud del municipio de Piedecuesta que se diseminó y multiplicó en red por toda la provincia de Soto en Santander y lentamente fue decayendo hasta desaparecer. "Claro está que si las demandas de un movimiento social particular son resueltas, éste tiende a perder fuerza en la medida en que su razón de ser comienza a desaparecer" (Frank \& Fuentes, 1987, p. 8).

No obstante, hoy los frutos del Movimiento Defensores del Agua prevalecen y se extienden a las luchas de los años dos mil. Los movimientos ambientales en Santander siguen resistiendo a proyectos en diferentes ecosistemas como son: la hidroeléctrica del río Sogamoso y el Proyecto Angosturas para explotación aurífera en el mismo Páramo de Santurbán (que acabamos de narrar) amparados en los mecanismos de participación que les brindó la Constitución del 91, la Ley 99/93, y la Ley 134 de $1994^{40}$. Mecanismos estos que han venido siendo objeto de 
reformas por parte del Estado para limitar la participación a que han dado lugar, como lo evidenciamos en el caso de los cabildos abiertos y la APA en resistencia al macroproyecto por parte del Movimiento Defensores del Agua.

Además, se observa cómo esta resistencia del caso de Santander en la primera década del dos mil, no es una lucha aislada. En el país se vienen prospectando hidroeléctricas en diferentes regiones, un proyecto que camina paralelo al fenómeno globalizador de la energía. De igual manera, las resistencias de los movimientos son locales, múltiples, diversas, como veremos en un próximo artículo donde se narra el Proceso Cívico en Defensa del río Guarinó y de "No al trasvase al río La Miel" que busca aumentar la generación de la hidroeléctrica La Miel I en el oriente Caldense, megaproyecto este que ha empoderado al movimiento ambientalista del municipio de La Dorada, departamento de Caldas (Colombia).

\section{BIBLIOGRAFÍA}

- Alexander, Jeffrey. (2000). Sociología cultural. Primera Edición. México: FLACSO-Anthropos.

- Álvarez, S. y Dagnino, E. (1999). Lo cultural y lo político en los movimientos sociales. En: Escobar A. El final del salvaje. Bogotá: CEREC-ICAN.

- Álvarez Tamayo, J. H. (1997). Se hace camino al andar. Aportes para una historia del movimiento ambiental colombiano. Bogotá: Ecofondo.

- Ángel Maya, A. (1997). Acariciando nuestros viejos fantasmas. En: Álvarez Tamayo, J. H. Se hace camino al andar. Aportes para una historia del movimiento ambiental colombiano. Bogotá: Ecofondo.

- Baiges Planas, F. (2001). ONGD: historias, aciertos y fracasos de quienes quieren ayudar al tercer mundo. Primera edición. Barcelona: Plaza y Janés Editores S. A.

- Castells, Manuel. (1999). La era de la información. Vol. 1. Madrid: Siglo XXI Editores.

- Cohen, Jean L. y Arato, Andrew (2000). Sociedad civil y teoría política. México: Fondo de Cultura Económica.

- Correa, Alonso. (1987). Anotaciones sobre la ideología del hábitat en nuestras ciudades. Práctica Barrial, 3. p. 6.

- Dagnino, Evelina. (2001). Cultura, ciudadanía y democracia: los discursos y prácticas cambiantes de la izquierda latinoamericana. En: Escobar, A.; Álvarez E., Sonia y Dagnino, E. (dirs.), Política cultural y cultura política. Bogotá: Taurus-ICANH.

- Escobar, Arturo. (1999). El final del salvaje. Bogotá: CEREC-ICAN.

- Escobar, A.; Álvarez E., Sonia y Dagnino, E. (2001). Política cultural y cultura política. Bogotá: Taurus-ICAN.

- Frank, Gunder A. y Fuentes, M. (1987). En torno a los movimientos sociales. Primer borrador de traducción 
Javier Sáenz. Bogotá: Investigación Participativa y Educación Popular, Colección Orlando Fals Borda.

- Fukuyama, Francis. (1992). El fin de la historia y el último hombre: la interpretación más audaz y brillante de la historia presente y futura de la humanidad / Francis Fukuyama; traducción de P. Elías. Editorial Planeta Colombiana.

- García, Martha C. (2001). Luchas y movimientos cívicos en Colombia durante los ochenta y los noventa, transformaciones y permanencias. En: Archila, M. y Pardo, M. Movimientos sociales, Estado y democracia en Colombia. Primera edición. Bogotá: UNAL-ICANH.

- Grueso, L.; Rosero, C. y Escobar A. (2001). El proceso de organización de comunidades negras en la región sureña de la costa Pacífica de Colombia. En: Escobar, A.; Álvarez E., Sonia y Dagnino, E. (dirs.). Política cultural y cultura política. Bogotá: Taurus-ICANH.

- Gutiérrez S., Francisco. (1998). La ciudad representada. Bogotá: T.M. Editores-IEPRI.

- Habermas, Jürgen. (1981). La reconstrucción del materialismo histórico. Primera edición. Madrid: Taurus.

- _ (1998). Facticidad y validez. Madrid: Editorial Trotta S. A.

- Hernández, M. y Villegas H., Pablo. (2003). Ideología y acción del movimiento ambientalista colombiano. Tesis de pregrado (Ciencias Políticas). Universidad Nacional de Colombia, Bogotá. No publicada.

- Jiménez Martín, Andrea Carolina. (2008). Democracia y neoliberalismo. Medellín: La Carreta Editores E. U.

- McAdam, D.; McCarthy, J. y Zald, M. (1999). Movimientos sociales: perspectivas comparadas. Madrid: Istmo.

- Martínez Alier, J. (2004). El ecologismo de los pobres conflictos ambientales y lenguajes de valoración. Barcelona: Icaria, Antrazit-Flacso.

- Melucci, Alberto. (2002). Acción colectiva, vida cotidiana y democracia. México: El Colegio de México.

- Palomino, Gonzalo. (1997). SOS Ecológico SOS. En: Álvarez Tamayo, J. H. Se hace camino al andar. Aportes para la historia del movimiento ambiental en Colombia Bogotá: Ecofondo.

- Paoli, María C. y Telles da Silva V. (2001). Derechos sociales: conflictos y negociaciones en el Brasil contemporáneo. En: Escobar, A.; Álvarez, S. y Dagnino, E. (dirs.). Política cultural y cultura política. Bogotá: Taurus-ICANH.

- Parroquia Nuestra Señora de la Esperanza. (1998). Memorias, "10 Años Sembrando Esperanza 19881998". Piedecuesta.

- Pratt, Mary L. (2001). ¿Hacia dónde? ¿Y luego? En: Escobar, A.; Álvarez, S. y Dagnino, E. (dirs.). Política cultural y cultura política. Bogotá: Taurus- ICANH.

- Ruiz, Juan P. (1997). Fortalecer un movimiento con capacidad de resolver desde la política y desde la tecnología los problemas ambientales. En: Álvarez Tamayo, J. H. Se hace camino al andar. Aportes para 
una historia del movimiento ambiental colombiano. Bogotá: Ecofondo.

- Tobasura Acuña, I. (2004). Los movimientos ambientales y la política ambiental en Colombia en los años noventa. Manizales: Universidad de Caldas.

\section{OTRAS FUENTES}

\section{Entrevistas}

- Beltrán, Joaquín. Enero 3 de 2009, Bucaramanga.

- Beltrán Quesada, Orlando. Enero 2 de 2009, Bucaramanga.

- Gutiérrez, José del R. Julio 26 de 2005, Piedecuesta.

- Guzmán, Héctor. Febrero 20 de 2009, Bogotá.

- Moreno Rojas, Fernando. Diciembre 29 de 2008, Piedecuesta.

- Prada, Álvaro. Enero 13 de 2009, Bucaramanga.

- Puente Brugés, Jairo. Enero 15 de 2009, Bucaramanga.

- Reyes, Alfonso. Julio 23 de 2005, Piedecuesta.

\section{Conferencias}

- Castro, José E. (1998). Formación de los monopolios en el Valle de México siglos XV-XIX. Conferencia presentada en el Simposio Internacional Norbert Elías y las ciencias sociales a finales del siglo XX, UIS-UNAL, junio, Bucaramanga.

\section{Periódicos}

- El Espectador. 10 de agosto de 1998. "Breves Nacionales, Agua para Bucaramanga". p. 13a.

- _ Magazín Dominical, 11 de abril de 1999. "¿Y del Guavio qué?" Álvaro Ávila Bernal.

- 14 de septiembre de 2008. "Serranía de los Cobardes". Alfredo Molano Bravo. p. 53.

- Vanguardia Liberal. 5 de noviembre de 1992. "Al rescate de Cobardes". p. 4c.

- 5 de febrero de 1993. "Dos años más entre el agua". p. 3b.

- 22 de julio de 2000. "Protesta Ambiental". p. 1.

- 28 de febrero de 2001. "No habrá Nuevo

. 23 de mayo de 2008. "Bumangueses tendrían crisis del agua en cinco años". Bucaramanga. p.1b.

\section{Fotografías}

- Archivo personal Ariel Edmundo Tarazona Pedraza.

- Periódico Vanguardia Liberal. 
1. Estudio cualitativo en el marco de la tesis de Maestría en Sociología de la Universidad Nacional de Colombia sede Bogotá, titulada: "Lo Cultural y lo Político del Movimiento Ambientalista Colombiano a partir de 1990", dirigida por la profesora Astrid Ulloa Cubillos.

2. Sociólogo, Magíster en Sociología de la Universidad Nacional de Colombia sede Bogotá. Integrante de los grupos de investigación: Cultura y Ambiente (Categoría $B$, Colciencias) y del seminario de línea de Historia Ambiental, expresión del grupo de Investigación Historia-Ambiente-Política (Categoría A, Colciencias). aetarazonap@gmail.com

3. El Área Metropolitana de Bucaramanga está conformada por la conurbación de los municipios de Bucaramanga, Floridablanca, Girón y Piedecuesta.

4. Se corrobora la asiduidad de líderes de estas organizaciones en las invitaciones a encuentros para la discusión, en una carta del 17 de marzo de 1997 en Piedecuesta y firmada por María Isabel Álvarez, vicepresidente de la Asociación Comunal, José del Rosario Gutiérrez del Consejo Municipal de Desarrollo Rural y Jhaneth Vera del Comité de Derechos Humanos, quienes convocan a la comunidad en general a un conversatorio sobre: "EL AGUA, informémonos y formémonos para poder decidir" (Archivos en torno al Movimiento Defensores del Agua).

5. Dentro de los organizadores del Cabildo Abierto por la Vida del 3 de noviembre de 1991, figuran: la Alcaldía Municipal, el Equipo Parroquial de Animación Pastoral, el Comité Estudiantil Bain, Asofique, Pastoral Social de Bucaramanga, Microempresa San Rafael, la Cooperativa Tabacalera de Piedecuesta, el Hospital Integrado San Juan de Dios, Comité Campesinos sin Tierra, el Centro de Salud, la Parroquia Nuestra Señora de la Esperanza, las Juntas de Acción Comunal, Coopcentral y el Club Rotario de Piedecuesta (ver: Vanguardia Liberal del 3 de noviembre de 1991, p. Metropolitana).

6. El padre Vicente Duarte, quien participó en la mesas de concertación postaudiencia pública ambiental en compañía de otros grupos.

7. Fernando Moreno Rojas, Abogado de profesión y quien en una carrera de asensos escaló por diferentes cargos locales en Piedecuesta, como el de Inspector de Policía, asesor jurídico de la alcaldía, Personero Municipal y Alcalde de la población.

8. Quienes participaban de estas primeras discusiones eran personajes de la localidad, entre los más destacados: María Isabel Álvarez, Jhaneth Vera, Doris Díaz Benavides, Ofelia Morantes, Margarita Arias, José del Rosario Gutiérrez, Juan Carlos Cortés, Alfredo Barajas, Fadul Gonzalo Méndez, Alejandro Barajas, Gonzalo Sánchez, Jesús Caballero, William Alarcón Rojas, Óscar Cruz, Óscar San Miguel.

9. Memorias Segundo Cabildo Abierto "Aguas y Vida", Piedecuesta, 11 de noviembre de 1996, p. 6. Este boletín aparece como autoría de la Asociación de 
Defensores del Agua de Piedecuesta y Municipios Vecinos por la confluencia de diferentes actores, mas sin embargo la redacción y elaboración de las Memorias es del Comité Regional de Derechos Humanos.

10. Los Cabildos Verdes se originan en 1986 en una política ambiental institucional del Inderena, que reformó los Consejos Verdes creados en 1984 a los cuales se les veía desde el Estado como un espacio político, social popular.

11. Orlando Beltrán Quesada, Administrador de Empresas y Especialista en Ingeniería Ambiental, docente de Universidades en Bucaramanga, y uno de los principales activistas del ambientalismo popular en Santander.

12. Esta distinción conceptual entre ecológicos y ambientales, obedece a que la ecología por ser la ciencia de las relaciones entre los organismos y el medio en que viven, hace a un margen al hombre, por tanto, los ecologistas buscaban más lo técnico y la conservación de los ecosistemas dejando otras dimensiones como la humana; en cambio, lo ambiental era más holístico abarcando lo político, cultural y lo social para conceptuar la crisis. Sin embargo, fue más una discusión que vino de afuera, traída a colación por miembros de los mismos grupos que participaban de discusiones internacionales. Porque como lo han reconocido los mismos líderes de los grupos, en los años setenta hubo algunos conservacionistas a ultranza y otros, los cuales al hombre, a la sociedad, a la naturaleza las veían también como un todo, haciendo parte de sus análisis.

13. Entre los principales destacados del Grupo Ecológico de la UIS están: Jaime Ardila, Clemencia Serrano (estudiantes en aquella época); Rosaura Gavilán, Deminson Martínez y Jairo Puente (profesores). Incluso tuvieron el apoyo del rector de la Universidad, Orlando Díaz Gómez.

14. Definido por Jairo Puente como "el primer agricultor ecológico de Santander", agrónomo oriundo del departamento de Nariño y radicado en San Vicente de Chucurí (Santander).

15. Jaime Ardila, Ingeniero Químico que también participó como estudiante del Grupo Ecológico de la UIS y que aunque termina pensionándose de ECOPETROL sigue en las luchas ambientales. Y su hermano Reynaldo "Ito" Ardila, Biólogo de la Universidad Nacional, aficionado a la fotografía y el periodismo, quien más adelante termina incursionando en el movimiento guerrillero Ejercito de Liberación Nacional, y muere trágicamente en combates con el Ejercito Nacional colombiano en inmediaciones del páramo de Berlín (Santander).

16. Hacían parte de este colectivo: Adan, Afonat, Asodeaguas, Cabildo Verde de Girón, Censat Agua Viva, Codesa, Cordeminas, Cordesco, Corfauna, Ecoverde, Funderioro, El Porvevir, Sol de Oriente, Veeduría Ambiental de Santander, Verde Limpio, Zua 
Quetzal, Comité Ecológico La Esmeralda, Comité Ecológico San Lorenzo, Comité Ecológico Puerta del Sol, Grupo Cegam/UIS, Grupo Facundo Navas.

17. Destacados miembros asumen la lucha como: Carlos Eslava, Hilda Flores, Arturo Barajas, Javier Rondón, William Cristancho, Emilio Arenas, Jairo Puente Brugés, Hernando Corrales.

18. Diego Alejandro Muñoz (2000) hace mención a este tópico de las ONGAS ambientales y que es reseñado en el documento del ambientalismo popular titulado: "El ambientalismo y el eclecticismo social", p. 1.

19. Los nuevos movimientos también tienen un lado "ofensivo" en que suponen esfuerzos para influir en los actores de la sociedad política, para que tomen decisiones políticas e inicien reformas adecuadas a las nuevas identidades colectivas.

20. Este cabildo fue convocado por el Concejo de Piedecuesta en concordancia con la actitud ofensiva del Movimiento de Defensores del Agua. Se expusieron 27 ponencias y fue el escenario propicio para hacer pedagogía entre sociedad civil y sociedad política sobre los efectos negativos y positivos del macroproyecto y alternativas al mismo. Al finalizar se estrecharon los vínculos entre el Movimiento y las autoridades locales con el triunfo obtenido.

21. Jairo Puente, pregunta: ¿Cuándo la CDMB ha dicho no a una licencia ambiental para construcción? (ver: Curso-taller, Gestión Ambiental en Páramos en Panorama Ambiental, UIS septiembre 18 de 1998. Al igual, en Vanguardia Liberal también se ventiló este tema el 16 de diciembre de 1997, p. Bucaramanga).

22. Cohen y Arato (2000) citan a Hannah Arendt, para indicar que: "sólo en un espacio público puede surgir la opinión pública" (p. 408).

23. Es a través de la "política de influencia" que líderes del Movimiento Defensores del Agua hacen aliados en las corporaciones de la sociedad política. Alfredo Barajas atrajo al diputado conservador Ángel de Jesús Becerra Ayala, abriéndose el debate en la Asamblea Departamental de Santander. Carlos Lizarazo mantuvo al tanto del macroproyecto al Senador de la República de Colombia Jimmy Chamorro de Compromiso Cívico Cristiano. Alejandro Barajas con su cruce de cartas e invitaciones a los grupos políticos del serpismo y Laicos por Colombia. Juan Carlos Cortés en su cotidiana actitud defensiva y ofensiva sobre diferentes partidos políticos en Piedecuesta.

24. Asojuntas (María Isabel Álvarez), Asodeaguas, Asodefusan (Roberto Camacho), veeduría ciudadana, parroquia San Francisco Javier.

25. En estos momentos se vinculan a la lucha: María Nancy Acevedo, María Judith Joya Roldado, Aydé Corea Daza, Rumaldo Vásquez, Patricia Rico, José David Velasco, entre otros.

26. La Universidad Autónoma de Bucaramanga es propiedad de la familia Puyana, propietaria a la vez de la constructora URBANAS. 
27. Se posibilitó una multitudinaria concentración de habitantes urbanos y rurales de los municipios afectados, especialmente de la localidad de Piedecuesta. "En audiencia se comenzó a mojar la palabra", tituló Vanguardia Liberal (18-02-1999). Arribaron las comunidades con la bandera nacional y pancartas alusivas a la defensa de las aguas, de la biodiversidad, de los páramos, de su economía campesina, en últimas, de la vida.

28. Onécimo Caviedes González, Geólogo de la Universidad Industrial de Santander -UIS-, quien con sus argumentos y críticas al macroproyecto abrió una discusión importante en el conocimiento experto de la Sociedad Santandereana de Geólogos y la UIS.

29. Entre los estudiantes destacados en estas convocatorias y que se vincularon a la Red, estuvieron: Sonia Pérez, Fabio Velasco, Patricia Reyes, Darío Vesga, Magda Liliana González.

30. José del Rosario Gutiérrez campesino del corregimiento de Umpalá en Piedecuesta y líder nativo del Movimiento Defensores del Agua, quien era un nodo importante con la red de organizaciones tradicionales como las JAC, ANUC, COMUDE, Asociación de Estudiantes de Bachillerato Rural, y quien comenzó a hacerse puente entre estas organizaciones y la institucionalidad local de Piedecuesta.

31. Invitando al Sociólogo Emilio Arenas al pleno del Concejo, quien expuso sus tesis sobre la carencia de un estudio de población que sopesara el megaproyecto. Y de la alternativa de nuevos poblamientos de Bucaramanga hacia el municipio de Sabana de Torres con la construcción de la vía paralela al antiguo carril férreo, que evitaría que la ciudad de Bucaramanga quedara aislada del flujo comercial y no dependiera solo de las vías de cordilleras de los antiguos caminos del reino [Arenas (1998); Vanguardia Liberal, 13 de mayo de 2001] y que en adelante se posicionó como una propuesta que toma el Movimiento Defensores del Agua como estrategia de lucha. No obstante, la clase dirigente de Santander solo vino a comprender esta propuesta diez años después, luego del aislamiento que vivió la ciudad de Bucaramanga con la ola invernal de diciembre de 2010. La ciudad de Bucaramanga quedó sitiada al solo depender de las vías de los antiguos caminos cordilleranos que se derrumbaron, hoy ya existe gestión en torno de la construcción de la vía paralela a la vía férrea, lo que pondrá a Bucaramanga más cerca del circuito del centro del país y de la costa Caribe.

32. Al igual el sindicato de la CAMB, luego de la APA, convocó en el Concejo Municipal de Bucaramanga a un Cabildo Abierto el 8 de abril de 2000. Allí los concejales propusieron llevar a Consulta Popular el tema del macroproyecto. Idea que el Movimiento Defensores del Agua no respaldaba, porque ya la APA había recogido el suficiente acervo probatorio de rechazo al macroproyecto. 
33. Audiencias Públicas Ambientales: Construcción Horno Incinerador de Residuos Sólidos Hospitalarios, Bucaramanga, mayo de 1999; Estación de Servicio Terpel junto al conjunto Miradores de San Lorenzo, Bucaramanga, junio de 1999; Viabilidad Ambiental Parqueaderos San Pío, Bucaramanga diciembre de 2002; Planta de Tratamiento de Residuos Sólidos, construcción de Relleno Sanitario, finca Alta Gracia, municipio de Girón, marzo de 2003; Hidroeléctrica del río Sogamoso 2009; Proyecto Explotación de Minerales Auroargentíferos denominado "Angostura", 4 de marzo de 2011.

34. Facilitaron esta labor: Flaminio Meza, Haroldo Vásquez.

35. Fukuyama (1992) alude: "El concepto subyacente en el de 'reconocimiento' no lo inventó Hegel. Es tan viejo como la filosofía política occidental, y se refiere a una parte enteramente familiar de la personalidad humana [...]. La parte del hombre que siente la necesidad de dar un valor a las cosas, a uno mismo en primer lugar, pero también a los otros hombres, a las acciones y a los objetos que nos rodean. Esta parte de la personalidad es la fuente fundamental de las emociones de orgullo, ira y vergüenza, y no puede reducirse al deseo, por un lado, ni a la razón por el otro. El deseo de reconocimiento es la parte de la personalidad humana más específicamente política, porque es la que empuja al hombre a querer afirmarse a sí mismo sobre los demás, y por tanto a la condición de "sociabilidad asocial" de Kant" (pp. 231-232).

36. Es Ingeniero Civil de profesión, quien elaboró el Plan de Desarrollo del Área Metropolitana para la antigua Asociación de Municipios del Área de Bucaramanga AMAB-, luego participó en la dirección de proyectos de la constructora URBANAS, más adelante acompañó la administración de Carlos Virviescas Pinzón (exdirector de la CDMB durante 13 años) como Secretario de Obras Públicas de la alcaldía de Bucaramanga y desde 1986 hasta el año 2000 asume la gerencia de la CDMB.

37. Es Ingeniero Civil, que laboró en la CAMB durante todo este proceso de solicitud de licencia para el macroproyecto y actualmente es gerente del Proyecto Embalse de Bucaramanga.

38. Titulares como los siguientes en Vanguardia Liberal lo confirman: "Bumangueses tendrían crisis de agua en quince años, sus fuentes hídricas amenazan con secarse" (23-05-2008, p. Bucaramanga); "En 2011 habría racionamiento del agua potable, habla el Gerente del Acueducto" (12-04-2009, p. principal).

39. En el año 2001 se informaba por el Sindicato de la CAMB cómo los estudios de factibilidad ascendían en ese momento a más de siete mil millones de pesos o sea 3,2 millones de dólares, $20 \%$ de lo que costarían los estudios de interventoría y asesoría de la primera etapa de la obra, sin que al momento se hubiera aprobado el proyecto en lo financiero y lo ambiental. A la vez se mostraba cómo el consorcio INGETEC-ETA en el caso de los estudios del megaproyecto demandó 
un tribunal de arbitramiento que obligó a la CAMB a pagar sobrecostos por valor de $\$ 1500$ millones de pesos.

40. El 29 de abril de 2009, diez años después de la Audiencia Pública Ambiental del macroproyecto, se realizó la Audiencia Pública Ambiental de la Hidroeléctrica del río Sogamoso. En marzo 4 y 8 de 2011 se realizó la Audiencia Pública Ambiental para el proyecto Explotación de Minerales Auroargentíferos denominado "Angostura" (minería de oro a cielo abierto), donde en un movimiento que desde la sociedad civil integró en su cometido en un bloque homogéneo a la sociedad política y a la sociedad económica, logró que la compañía GREISTAR RESOURGES LTDA. propietaria del proyecto retirara el proyecto ante la negativa del Ministerio de Ambiente y de la Procuraduría General de la Nación. Este movimiento ambientalista fue ampliamente reseñado por los medios masivos nacionales de comunicación y requiere ser documentado para ver en detalle cómo se creó este bloque histórico de resistencia. 